\title{
MÉTODO ALTERNATIVO DE ENSAIO ACELERADO PARA AVALIAÇÃO DA RESISTÊNCIA NATURAL DE MADEIRAS AO ATAQUE DE FUNGOS APODRECEDORES
}

\section{MARIA BEATRIZ BACELLAR MONTEIRO}

Bióloga

Orientador: Prof. Dr. AMANTINO RAMOS DE FREITAS

Dissertação apresentada à Escola Superior de Agricultura "Luiz de Queiroz", da Universidade de São Paulo, para obtenção do título de Mestre em Ciências, Area de Concentração: Ciência e Tecnologia de Madeiras.

PIRACICABA

Estado de São Paulo - Brasil

Junho - 1997 
Dados Internacionais de Catalogaçăo na Publicação (CIP)

DIVISÃO DE BIBLIOTECA E DOCUMENTAÇĀO - Campus "Luiz de Queiroz"/USP

\author{
Monteiro, Maria Beatriz Bacellar \\ Método alternativo de ensaio acelerado para avaliaçåo da resistência natural \\ de madeiras ao ataque de fungos apodrecedores / Maria Beatriz Bacellar \\ Monteiro. - - Piracicaba, 1997. \\ $73 \mathrm{p}$. \\ Dissertaçăo (mestrado) - - Escola Superior de Agricultura Luiz de Queiroz, \\ 1997. \\ Bibliografia.
}

1. Ensaio 2. Madeira (conservaçăo) 3. Resistência ao fungo I. Título 


\section{MÉTODO ALTERNATIVO DE ENSAIO ACELERADO PARA AVALIAÇÃO DA RESISTÊNCIA NATURAL DE MADEIRAS AO ATAQUE DE FUNGOS APODRECEDORES}

MARIA BEATRIZ BACELLAR MONTEIRO

Aprovada em: 29/08/1997

Comissão julgadora:

Prof. Dr. Amantino Ramos de Freitas

Prof. Dr. Mário Tomazello Filho

Prof. Dr. Messias Soares Cavalcante

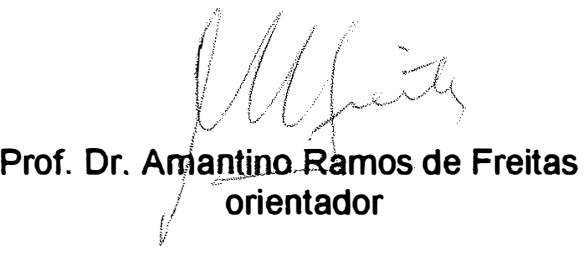


Para meu pai 


\section{AGRADECIMENTOS}

Ao Prof. Dr. Amantino Ramos de Freitas, cuja orientação e auxílio permitiram a realização deste trabalho.

Ao Prof. Dr. Marcio Augusto Rabelo Nahuz, Diretor da Divisão de Produtos Florestais, e ao Prof. Dr. Antonio Tadeu de Lelis, Chefe do Agrupamento Preservação de Madeiras, do Instituto de Pesquisas Tecnológicas do Estado de São Paulo - IPT, pelo apoio e incentivo.

À Fundação Coordenação de Aperfeiçoamento de Pessoal de Nivel Superior - CAPES, pelo auxílio financeiro.

Aos professores do Instituto de Pesquisas Tecnológicas do Estado de São Paulo-IPT e da Escola Superior de Agricultura "Luiz de Queiroz" - ESALQ, pelas informações prestadas ao longo do Curso.

À Prof. Dra. Estela Maris Andrade Forell Bevilacqua e equipe, do Instituto de Ciências Biomédicas da Universidade de São Paulo, pela cooperação na parte prática do estudo.

Ao Dr. Rubens Dias Humphreys, pelo auxílio nas análises estatísticas e revisão do documento.

Ao Paulo de Assis, pelo cuidado na obtenção dos corpos-deprova.

Aos colegas do curso, em especial, Geraldo, Gonzalo, Inês, Lorena e Zezé que, cada qual a seu modo, tornaram mais leve a realização deste trabalho.

Aos companheiros de todo o dia, meus amigos do Laboratório de Micologia do IPT, Adriana D. Carvalho Costa, Reginaldo Ramos de Oliveira e Sérgio Brazolin, pelo auxílio inestimável! Muito obrigada!

Ao Valdir e a todos os meus familiares e amigos, pela compreensão e apoio. 


\section{SUMÁRIO}

Página

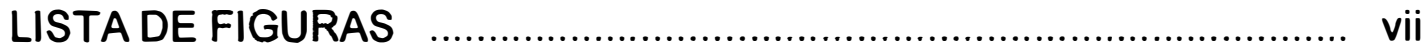

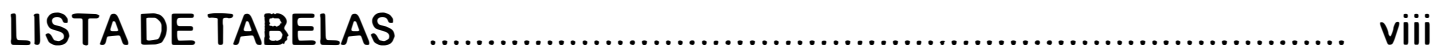

CURRICULUM VITAE .................................................................. ix

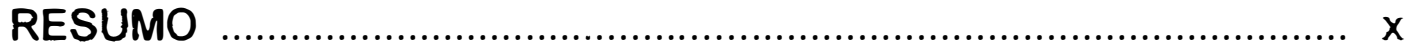

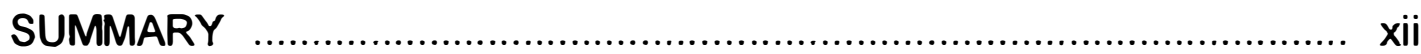

1 INTRODUÇÃO

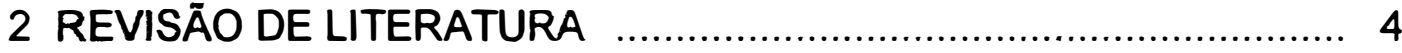

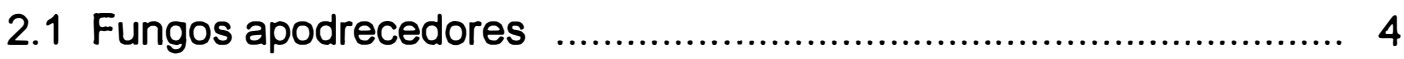

2.2 Espécie de fungo selecionada para este estudo f...................... 5

2.3 Durabilidade natural da madeira f............................................ 7

2.4 Ensaios para determinação da durabilidade natural ..................... 8

2.5 Ensaios laboratoriais alternativos f........................................... 12

3 MATERIAL E MÉTODOS …................................................ 15

3.1 Espécies de madeira ........................................................ 15

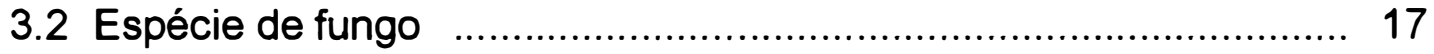

3.3 Corpos-de-prova .......................................................... 17

3.4 Procedimento para o método "soil-block" ................................... 18

3.5 Procedimento para o método "mini-agar-block" ......................... 19

3.6 Análises estatísticas f....................................................... 23

3.6.1 Análises para comparação da durabilidade natural das espécies de madeira nos dois métodos .............................. 23

3.6.2 Análises para verificar a influência dos fatores condicionamento e esterilização nos quatro tratamentos do método "mini-agar-block" ............................ 24

4 RESULTADOS ................................................................. 25 
4.1 Análises estatísticas

4.1.1 Comparação da durabilidade natural das

espécies de madeira nos dois métodos

30

4.1.2 Influência dos fatores condicionamento

e esterilização nos quatro tratamentos

do método "mini-agar-block" ................................................. 30

5 DISCUSSÃO

5.1 Comparação da durabilidade natural das

espécies de madeira nos dois métodos

5.2 Influência dos fatores condicionamento

e esterilização nos quatro tratamentos

do método "mini-agar-block"

6 CONCLUSŐES

ANEXOS 38

Anexo A - Tabelas de resultados para o método "soil-block" 38

Anexo B - Tabelas de resultados para o Tratamento I do método "mini-agar-block"

Anexo C - Tabelas de resultados para o Tratamento II do método "mini-agar-block"

Anexo D - Tabelas de resultados para o Tratamento III do método "mini-agar-block"

Anexo E - Tabelas de resultados para o Tratamento IV do método "mini-agar-block"

REFERÊNCIAS BIBLIOGRÁFICAS 58 


\section{LISTA DE FIGURAS}

Página

1 Distribuição dos corpos-de-prova do método "mini-agar-block", por grupo ou tratamento 22

2 Valores médios de perda de massa, expressos em porcentagem, para o método "soil-block" e Tratamento I do método "mini-agar-block"

3 Valores médios de perda de massa, expressos em porcentagem, para os quatro tratamentos do método "mini-agar-block" 


\section{LISTA DE TABELAS}

Página

1 Método "soil-block" - resultados de perda de massa

2 Tratamento I do método "mini-agar-block" resultados de perda de massa

3 Método "mini-agar-block"- resultados obtidos para os diversos tratamentos

4 Comparaçāo dos tratamentos para pinho-do-paraná 


\section{CURRICULUM VITAE}

Nome: Maria Beatriz Bacellar Monteiro

Data e local de nascimento: 31 de julho de 1957, São Paulo, SP

\section{Formação universitária}

Licenciatura em Ciências Biológicas e Bacharelado em Biologia, Instituto de Biociências da Universidade de São Paulo (São Paulo, SP, 1980)

\section{Cursos, estágios, congressos e publicaçōes}

- Estágio "Caracterização de espécies de fungos basidiomicetos (métodos de cultura "in vitro", microscopia óptica e eletrônica"), UCL, Bélgica, 1988.

- Prêmio Brasitest - melhor contribuição técnica, $17^{\circ}$ Seminário Brasileiro de Inspeção de Equipamentos, Rio de Janeiro, 1989.

- Participação como conferencista convidada do "FIRST LABS - Latin American Biodeterioration Symposium", Campos do Jordão, 1992.

- Publicação IRG/WP/2401-92 "Comparison between agar-block and soil-block methods for wood-destroying Basidiomycetes", 1992.

- Curso "Advances in Fungal Taxonomy", FTPQAT/IMI, Campinas, 1992.

- Participação, como conferencista convidada, "Seminário Estudio Tecnologico y Dendrologico del Genero Schinopsis en la Chiquitania y el Chaco Boliviano", Santa Cruz, Bolívia, 1994.

- Publicação "Identificação de fungos em revestimentos de argamassa com bolor evidente", Anais do ISBTA, 1995.

\section{Cargo atual}

Pesquisadora, responsável pelo Laboratório de Micologia do Agrupamento Preservação de Madeiras, Divisão de Produtos Florestais, Instituto de Pesquisas Tecnológicas do Estado de São Paulo S.A. - IPT. 


\title{
MÉTODO ALTERNATIVO DE ENSAIO ACELERADO PARA AVALIAÇÃO DA RESISTÊNCIA NATURAL DE MADEIRAS AO ATAQUE DE FUNGOS APODRECEDORES
}

\author{
Autora: MARIA BEATRIZ BACELLAR MONTEIRO \\ Orientador: Prof. Dr. AMANTINO RAMOS DE FREITAS
}

\section{RESUMO}

Com o objetivo de buscar um método alternativo acelerado que, usando a perda de massa como medida indireta da durabilidade natural de madeiras, seja um bom indicador desta propriedade, foram realizados dois ensaios concomitantes. O primeiro, desenvolvido de acordo como o método da norma ASTM D-2017 "Standard Method for Accelerated Laboratory Test of Natural Decay Resistance of Woods", conhecido como "soil-block", tem sido habitualmente utilizado para avaliação da resistência natural de madeiras ao apodrecimento. No segundo, método alternativo aqui denominado "mini-agarblock", as dimensões dos corpos-de-prova foram reduzidas e o substrato para o crescimento do fungo foi alterado.

Cinco espécies de madeira nativas do Brasil foram submetidas ao ataque do fungo Gloeophyllum trabeum (Pers.:Fr.) Murr., sob idênticas condições de temperatura e umidade relativa.

$O$ método de ensaio alternativo mostrou-se promissor e candidato à substituição do método "soil-block", por ter permitido, em curto espaço de tempo, a obtenção de perdas de massa maiores para todas as espécies de madeira ensaiadas.

Ambos os métodos classificaram as espécies de madeira da mesma forma, ou seja, formaram dois grupos, estatisticamente distintos. 
Os resultados de perda porcentual de massa, obtidos com a espécie de fungo utilizada não conseguiram, em nenhum dos métodos, separar espécies de madeira como a aroeira (Astronium sp) e a peroba-rosa (Aspidosperma polyneuron), que apresentam, em serviço, durabilidade natural bastante distinta.

Sugere-se, seja qual for o método de ensaio empregado, a revisão das espécies de fungos recomendadas pela norma ASTM D-2017 e a introdução de espécies de fungos nativas do Brasil, isoladas a partir de madeiras em deterioração. 


\title{
ALTERNATIVE ACCELERATED LABORATORY TEST METHOD OF NATURAL DECAY RESISTANCE OF WOODS
}

\author{
Author: MARIA BEATRIZ BACELLAR MONTEIRO \\ Adviser: Prof. Dr. AMANTINO RAMOS DE FREITAS
}

\section{SUMMARY}

Two assays were developed, using weight loss, to indirectly evaluate the natural durability of wood. The first assay, developed in accordance with the method ASTM D-2017, known as soil-block, has been used to evaluate natural resistance of woods against rotting. In the second procedure, called the mini-agar-block assay, the size of the proof block was reduced and the substrate for fungal growth was changed.

Five species of native Brazilian wood were infected with the fungus Gloeophyllum trabeum (Pers.: Fr.) Murr. under the same conditions of temperature and relative humidity.

The alternative method of assay proved to be an effective substitute for the soil-block test because the results were obtained in a shorter period of time and there were larger mass losses in all species of wood analyzed. All species of wood produced statistically distinct data with both procedures.

The results of percentage mass loss obtained were not able to show, in both methods, differences between species of wood like aroeira (Astronium sp) and peroba-rosa (Aspidosperma polyneuron), which have very distinct natural durabilities. It is suggested, for both methods, a revision of the 
fungal species recommended by the ASTM D-2017 method and the introduction of native Brazilian fungae species, isolated from rotting wood. 


\section{INTRODUÇÃO}

A madeira é um material orgânico sujeito à deterioração biológica devendo por esta, entre outras razões, ser utilizada criteriosamente.

Se o teor de umidade da madeira encontrar-se regularmente, e por períodos prolongados de tempo, acima do ponto de saturação das fibras, criam-se condições favoráveis ao desenvolvimento de fungos apodrecedores (Building Research Establishment-BRE, 1988). Estes, degradam as moléculas de celulose, hemiceluloses e lignina, constituintes das paredes celulares da madeira, utilizando-as como alimento. Alteram assim. a integridade estrutural da madeira, comprometendo sua resistência mecânica.

Para que se possam definir possíveis usos finais para uma determinada espécie de madeira ou compará-la, para efeito de substituição, com alguma espécie tradicionalmente utilizada, é importante determinar a sua durabilidade ou resistência natural ao apodrecimento. Duas espécies de madeira podem apresentar propriedades mecânicas semelhantes, porém, serem bem diferentes quanto à resistência natural ao apodrecimento. Um ensaio freqüentemente utilizado para essa determinação, conhecido internacionalmente como "soil-block", é baseado no método D-2017 da "American Society for Testing and Material (ASTM): Standard Method for Accelerated Laboratory Test of Natural Decay Resistance of Woods". Este método, utilizando a perda de massa de corpos-de-prova de madeira como medida indireta de sua durabilidade natural, fornece, como resultado, uma estimativa da resistência relativa de espécies de madeira ao ataque por fungos de podridão branca e parda. 
Apesar de ser considerado um ensaio acelerado, quando comparado ao processo de deterioração da madeira em serviço, o método ASTM exige um tempo mínimo de exposição aos fungos de 12 semanas, podendo se estender a 16 semanas. Este intervalo de tempo, acrescido daquele requerido para a preparação e montagem do ensaio, pode ultrapassar 20 semanas.

O setor industrial, principalmente 0 da construção civil que tem a madeira como uma de suas matérias-primas, está preocupado em selecionar as espécies que apresentam as melhores características físicas, mecânicas e de resistência natural ao ataque por agentes biológicos, em particular, fungos apodrecedores. A indústria por outro lado, ciente destes aspectos, não pode, na grande maioria das vezes, esperar por resultados de ensaios de avaliação da resistência natural de tão longa duração. Como resultado, normalmente acaba tomando decisões sem um embasamento técnico e científico adequado, o que prejudica, a longo prazo, a imagem da madeira no mercado.

Estudos sobre ensaios alternativos, que possam fornecer resultados seguros e em curto espaço de tempo para a indústria, têm sido uma preocupação constante dos pesquisadores que trabalham com ciência e tecnologia de madeiras.

O presente estudo teve como objetivo principal buscar um método alternativo ao "soil-block" que seja um bom indicador da resistência natural das madeiras, reduzindo o tempo de exposição dos corpos-de-prova aos fungos apodrecedores.

O desdobramento deste método alternativo em quatro diferentes experimentos teve como objetivo investigar a influência dos tipos de condicionamento e de esterilização recebidos pelos corpos-de-prova, antes de serem submetidos ao contato com o fungo apodrecedor. 


\section{REVISÃO DE LITERATURA}

\subsection{Fungos apodrecedores}

Muitas espécies de fungos são responsáveis pela deterioração da madeira e de produtos derivados da madeira, infectando-os em diferentes estágios de seu processamento, desde o abate da árvore até cada um de seus diversos usos finais. Estes fungos podem ser agrupados de acordo com semelhanças em seus efeitos sobre a madeira; estas semelhanças por sua vez, refletem as diferentes características fisiológicas e necessidades nutricionais dos organismos (Bravery, 1987).

Segundo Rayner \& Boddy (1988), uma das primeiras formas de classificação dos fungos apodrecedores foi o reconhecimento, em 1924, de duas classes básicas: a dos fungos responsáveis por uma podridão branca e a dos responsáveis por uma podridão parda na madeira. As duas classes de apodrecimento distinguem-se entre si, como o próprio nome indica, pelo aspecto macroscópico da madeira como um todo. Os fungos de podridão branca provocam uma alteração na cor da madeira, que se torna mais clara do que a sadia, adquirindo, além disso, uma consistência esponjosa. Os fungos de podridão parda também alteram a coloração da madeira que se torna mais escura do que a sadia. Esta alteração na cor é acompanhada, em estágios 
avançados de podridão parda, pela formação de fissuras paralelas e perpendiculares às fibras da madeira que adquire, além disso, uma consistência friável. Uma terceira classe de apodrecimento, descrita em 1954, é conhecida como podridão mole.

Segundo os mesmos autores, atualmente é de aceitação geral que as podridões brancas envolvem a degradação de todos os componentes químicos estruturais da madeira, incluindo a celulose - embora a lignina possa, em alguns casos, ser preferencialmente removida. As podridões pardas envolvem, tipicamente, a utilização dos mono e polissacarídeos da madeira. Os valores de remoção da lignina são irregulares mas em geral, pequenos. Highley (1987) entretanto, observou valores surpreendentemente altos de remoção de lignina para alguns fungos de podridão parda. Como exemplo, o autor cita Gloeophyllum trabeum (Pers.:Fr.) Murr. com uma remoção de $22 \%$ da lignina da espécie de madeira Acer rubrum L., família Aceraceae, quando esta apresentava $58 \%$ de perda de massa, em ensaio "soil-block".

\subsection{Espécie de fungo selecionada para este estudo}

Dentre os fungos responsáveis pela podridão parda da madeira destaca-se a espécie Gloeophyllum trabeum.

Segundo monografia de Hof ${ }^{1}$,citado por Eaton \& Hale (1993), a espécie de fungo Gloeophyllum trabeum, conhecida anteriormente como Lenzites trabea, pertence à Classe Hymenomycetes, Ordem Aphyllophorales,

\footnotetext{
${ }^{1}$ HOF, T. First draft of a monographic card for Gloeophyllum trabeum (Pers.: Fr.) Murr., International Research on Wood Preservation, Document No IRGNP/113; (version revised in 1978 published in Cockcroft, 1979).
} 
Família Polyporaceae. De acordo com Eaton \& Hale (1993), ocorre em situações diversas como: árvores em pé, toras abatidas e tocos, madeiras em contato com o solo, postes, dormentes, pontes, torres de resfriamento, barcos, madeiramento de telhado, molduras de janelas, etc. Ocorre na Austrália, Europa, Nova Zelândia, América do Norte e em Estados do Sul da África.

No Brasil, corpos-de-frutificação de Gloeophyllum trabeum foram coletados em dormente de madeira localizado em pilha de secagem, em usina de preservação, Bauru, SP (Milano et al., 1985).

Segundo Duncan \& Lombard ${ }^{2}$, citados por Eaton \& Hale (1993), o fungo Gloeophyllum trabeum provoca um apodrecimento rápido tanto em madeiras de coniferas quanto de folhosas. Apresenta as seguintes condições ótimas para crescimento micelial: temperatura em torno de $35^{\circ} \mathrm{C}$ e umidade entre 30 a $50 \%$. Suporta uma grande flutuação no conteúdo de umidade do ar. Exibe alguma tolerância ao arsênio e ao cobre, tolerando também o dessecamento.

Eslyn ${ }^{3}$, citado por Eaton \& Hale (1993), reporta uma perda de massa de 59 \% em madeira de Pinus spp ("southern pine") exposta, durante 12 semanas, ao fungo Gloeophyllum trabeum, em ensaio "soil-block".

Essa espécie de fungo pode, sob condições favoráveis, ser prontamente induzida a frutificar em cultura. O corpo-de-frutificação é fino e marrom, variando de poróide a lamelado. Basidiosporos têm de 7-11 $\times 3$ $4,5 \mu \mathrm{m}$ (Eaton \& Hale, 1993).

\footnotetext{
${ }^{2}$ DUNCAN, C.G., LOMBARD, F.F. Fungi associated with principal decays in wood products in United States, U.S. Forest Service Research Paper WO-4, Washington.

${ }^{3}$ ESLYN, W.E. Utility pole decay, part 4: growth-temperature relationships and decay capacities of eleven major utility pole decay fungi. Holzforschung, 40 (2), 69-77.
} 


\subsection{Durabilidade natural da madeira}

Segundo Rayner \& Boddy (1988), o tempo de vida útil de uma determinada espécie de madeira e de seus produtos derivados depende, basicamente, das condições às quais este material será submetido durante e após seu processamento e da durabilidade intrínseca da espécie botânica utilizada, ou seja, da sua durabilidade natural.

$\mathrm{Na}$ Grã-Bretanha o termo durabilidade natural refere-se geralmente à resistência ao ataque por fungos de uma madeira em serviço. A durabilidade da maioria das madeiras varia de forma considerável e mesmo peças retiradas da mesma árvore irão apresentar com freqüência grandes diferenças. Sendo assim, somente é possivel falar-se em durabilidade natural em termos aproximados (BRE, 1969).

De modo geral, o conceito de durabilidade natural está sempre associado ao cerne de determinada espécie de madeira, na medida em que, na prática, o alburno de todas as espécies de madeira é considerado não durável ou perecivel quando submetido ao ataque por fungos apodrecedores (BRE, 1977; Comité Européen de Normalisation - CEN, 1990 e Eaton \& Hale, 1993).

Segundo Eaton \& Hale (1993), a durabilidade natural de uma espécie de madeira é condicionada pelas vias de acesso dos organismos à madeira e por sua composição química. Em relação às vias de acesso, a movimentação dos fungos no interior da madeira é facilitada pelo sistema natural de passagens dos elementos celulares que a compõem. Embora as hifas dos fungos possam, por pressão mecânica e ação enzimática 
extracelular, penetrar diretamente nas paredes celulares, a natureza, distribuição e tamanho dessas passagens e as comunicações entre elas são cruciais na determinação de padrões de colonização. Os elementos axiais, principalmente os vasos em folhosas e traqueídeos em coniferas, são as principais vias de acesso para os fungos basidiomicetos de podridão branca e parda. Seguem em importância, os elementos radiais e, por último, os tangenciais. Tiloses, gomas e resinas funcionam como verdadeiras barreiras, dificultando a penetração dos fungos no interior da madeira.

Em relação à composição química, os produtos do metabolismo primário, como açúcares solúveis, lipideos e peptídeos, e os compostos armazenados na madeira, como o amido, fornecem o principal suprimento de fontes de carbono de fácil assimilação para fungos e outros organismos. No entanto, essas substâncias ocorrem em pequena quantidade na madeira, sendo rapidamente consumidas durante o processo de colonização. Os componentes da parede celular são as principais fontes de carbono para o crescimento dos fungos na madeira. Dentre estes, a celulose é usualmente o componente dominante, tipicamente 40 a $50 \%$ do peso seco para madeiras sadias, tanto para coniferas quanto para folhosas. As hemiceluloses - xilanas e glucomanas - ocorrem em uma taxa de 25 a $40 \%$ em folhosas de regiōes temperadas e de 25 a $30 \%$ em coniferas. As ligninas são substâncias aromáticas resultantes da polimerização de sub-unidades de fenil-propanóide e constituem um tipo de molécula bastante complexo. Ocorrem em uma taxa de 25 a $35 \%$ em coniferas, e de 18 a $25 \%$ em folhosas da região temperada. Considerando ainda a composição química da madeira, os extrativos, ou seja, aqueles componentes que podem ser removidos com 
solventes orgânicos ou com água, têm uma importância significativa na durabilidade natural da madeira. A quantidade, tipo e distribuição dos extrativos é variável, mas eles são mais abundantes no cerne. Os extrativos afetam 0 desenvolvimento dos fungos de diferentes maneiras: podem servir como fonte de carbono, podem estimular o crescimento ou, e é por esta característica que são mais conhecidos, podem inibir este crescimento. Dentre os extrativos responsáveis por uma inibição do crescimento estão os terpenos e derivados, as tropolonas, e os compostos fenólicos, como flavanóides, estilbenos, quinonas, lignanas e taninos.

Estudos práticos para avaliação da durabilidade natural têm recebido considerável atenção dos pesquisadores, devido às orientações que fornecem sobre o uso final para determinada espécie de madeira, evitando perdas econômicas decorrentes de tratamentos preservativos desnecessários e/ou substituição precoce de madeiras apodrecidas (Rayner \& Boddy, 1988).

\subsection{Ensaios para determinaçăo da durabilidade natural}

Duas principais abordagens têm sido adotadas para a avaliação da durabilidade natural da madeira: os ensaios de campo e os ensaios laboratoriais (Rayner \& Boddy, 1988).

Ensaios de campo reproduzem mais fielmente as condições reais de utilização da madeira em serviço e podem fornecer informações mais precisas sobre sua durabilidade natural e possiveis usos finais. Exigem porém, um longo tempo de exposição da madeira em campos de apodrecimento que, 
para as espécies muito duráveis, deve ser superior a 15 anos (Cavalcante et al., 1985; Cavalcante et al., 1982; Cavalcante et al., 1978; Cavalcante, 1971; Fosco Mucci et al., 1992 e Lepage, 1970). Requerem, além disso, toda uma infra-estrutura para instalação de campos de apodrecimento e para o acompanhamento periódico da evolução da deterioração.

Os ensaios laboratoriais, segundo Cavalcante (1971), embora forneçam dados a respeito do comportamento da madeira em serviço não são definitivos. Entretanto, constituem uma boa alternativa quando empregados para a obtenção de informações em curto intervalo de tempo.

De acordo com Da Costa (1975), apesar de muitos autores terem reservas quanto à capacidade de predição dos ensaios laboratoriais, estes seriam a única fonte existente de informações objetivas para a previsão do comportamento em serviço de uma espécie de madeira ao longo do tempo. O autor acredita ainda que culturas puras de basidiomicetos fornecem resultados rápidos e reprodutíveis simulando, melhor do que outros grupos de microrganismos, as condiçōes de campo durante um rápido processo de apodrecimento. Outros microrganismos, como por exemplo, fungos e bactérias responsáveis por uma podridão mole na madeira, podem ser importantes como precursores ou comensais, mas um apodrecimento severo, conduzindo a falhas da madeira em serviço, é usualmente provocado por uma cultura pura de basidiomiceto.

Dentre os ensaios laboratoriais para avaliação da durabilidade natural das madeiras contra fungos de podridão branca e parda, pertencentes à subdivisão Basidiomycotina, existem duas principais abordagens: a) 0 método conhecido como "agar-block", constituiu a base para várias normas 
européias, agora unificadas na Norma EN 113, sob a denominação "Détérmination du seuil d'efficacité contre les champignons basidiomycètes lignivores cultivés sur milieu gelose" (CEN, 1980); b) o método "soil-block", que originou a norma americana ASTM D 2017 "Standard Method for Accelerated Laboratory Test of Natural Decay Resistance of Woods" (Rayner \& Boddy, 1988), e tem sido adotado também no Brasil (Cavalcante, 1971; Monteiro et al., 1992).

No método de ensaio "agar-block", desenvolvido inicialmente por Liese et al. ${ }^{4}$, citados por Rayner \& Boddy (1988), para avaliar a eficiência de produtos preservativos, corpos-de-prova de madeira são tratados com diluições seriadas de soluções preservativas, secos em estufa, esterilizados e colocados sobre culturas puras de fungos apodrecedores crescendo em meio de cultura ágar/malte. Este método recomenda a utilização de corpos-deprova de cerne, com dimensões de $50 \times 25 \times 15 \mathrm{~mm}$, com a maior dimensão paralela às fibras da madeira, separados do substrato por meio de suportes de vidro ou outro material inerte (CEN, 1980).

O método de ensaio "soil-block", desenvolvido por Leuritz ${ }^{5}$, citado por Rayner \& Boddy (1988), é uma modificação do método "agar-block" e consiste em submeter corpos-de-prova das espécies de madeira a serem ensaiadas a culturas puras de fungos apodrecedores, crescendo sobre um suporte de madeira de baixa resistência natural em contato direto com solo úmido. O método preconiza a utilização de corpos-de-prova de cerne, com

\footnotetext{
${ }^{4}$ LIESE, J., NOWAK, A., PETERS, F., RABANS, A. Toximetrische Bestimmung von Holzkonsevierungsmittlen. Agnew. Chem., v48, n.11, 1935.

${ }^{5}$ LEURITZ, J. A wood soil contact culture technique for laboratory study of wood destroying fungi, wood decay and wood presenvation. Bell Syst. Tech. J., v.25, p.102-135, 1946.
} 
dimensões de $25 \times 25 \times 9 \mathrm{~mm}$, obtidos de maneira que a menor dimensão seja paralela às fibras da madeira (ASTM, 1986).

Ambos os métodos de ensaio utilizam a perda de massa como principal critério para avaliar a deterioração da madeira e podem levar mais de 5 meses para fornecer resultados (Rayner \& Boddy, 1988).

No Brasil, desde a década de 40 , já se realizam ensaios para avaliação da resistência natural de madeiras, e resistência de madeiras impregnadas com produtos preservativos, contra fungos apodrecedores.

Azevedo (1943), com o objetivo de avaliar a influência dos fenóis de creosoto na resistência de madeiras tratadas, utilizou, com algumas adaptações, o método de ensaio seguido pelo "Bell Telephone Laboratories" 6 de Nova York, EUA. A partir de 1943 este método foi adotado pelo Instituto de Pesquisas Tecnológicas do Estado de São Paulo - IPT (Ghilardi, 1961). No método IPT a resistência da madeira era avaliada de acordo com os seguintes critérios: a) crescimento ou não do micélio dos fungos sobre os corpos-deprova; b) vigor deste crescimento; c) perda de massa dos corpos-de-prova devida à ação dos fungos; d) diminuição da resistência mecânica da madeira, verificada por meio de ensaios de fendilhamento.

Ghilardi (1961) relata a substituição no IPT, por volta de 1951, do ensaio de fendilhamento pelo de flexão estática. Tal substituição teve como objetivo dar maior sensibilidade ao método e observar, em espaço de tempo relativamente curto (120 dias) a ação dos fungos sobre a madeira.

Cavalcante (1971) descreve dois métodos de avaliação da resistência de madeiras ao ataque de fungos xilófagos. Em um deles a avaliação é feita pela perda da resistência da madeira à flexão estática e no

${ }^{6}$ WATERMAN, R.E., LENTRIZ, Y.L., HILL, C.B. Ind. Eng. Chem. Anal. Ed. 10, 306 (1938). 
outro pela perda de massa. Neste trabalho o autor comenta que, embora ambos os métodos mostrem resultados equivalentes, o método de perda de massa tem sido mais utilizado devido às facilidades que apresenta na obtenção dos corpos-de-prova, na avaliação dos resultados e no menor período de exposição.

A partir de 1973, o IPT passou a adotar o método de ensaio ASTM D-2017 para determinação da resistência natural da madeira ao ataque de fungos apodrecedores.

Bravery \& Lavers (1971), com o objetivo de avaliar o uso do critério perda de resistência mecânica como forma de medir mais rapidamente a taxa de apodrecimento por fungos basidiomicetos, trabalharam com pequenos corpos-de-prova $(75 \times 5 \times 5 \mathrm{~mm})$, comparando medidas de perda de massa com medidas de perda de resistência à flexão estática. Os autores concluiram que, para este tipo de corpo-de-prova com pequenas dimensōes, as medidas de resistência à flexão não mostraram ser um critério mais sensivel para detectar 0 ataque por fungos do que as de perda de massa.

\subsection{Ensaios laboratoriais alternativos}

Muitos autores têm proposto ensaios laboratoriais alternativos, com o objetivo de reduzir o tempo de exposição da madeira, com e sem tratamento preservativo, aos fungos apodrecedores. A maior parte destes ensaios tem como objetivo avaliar a eficiência de produtos utilizados para 0 tratamento de madeiras. 
Dickinson (1974) propõe uma nova técnica para triagem de produtos fungicidas potenciais a serem utilizados para a preservação de madeiras. Em seu trabalho, o autor descreve um método que consegue reduzir para 3 semanas essa seleção preliminar de produtos. O método emprega um substrato de papel de filtro inoculado com a espécie de fungo de interesse, colocado no centro de outro disco de papel de filtro, maior do que o primeiro, previamente tratado com a concentração do produto a ser avaliado e umedecido com uma solução salina. Uma incubação de 2 semanas permite comparar produtos/concentrações por meio de medidas do diâmetro de crescimento da colônia fúngica. O método apresentado permite a obtenção de resultados adequados para a seleção preliminar de produtos fungicidas, fornecendo dados para a realização de ensaios conforme método da norma BS 838: 61 , atualmente norma européia EN-113: 80, tradicionalmente empregada para a avaliação de produtos preservativos da madeira.

Bravery (1978), em estudo para avaliar a eficiência fungicida de produtos preservativos de madeira, parte do princípio de que a taxa de apodrecimento da madeira pode ser acelerada por meio da redução da massa dos corpos-de-prova, apresentando um método simples, no qual corpos-deprova de pequenas dimensões $(30 \times 10 \times 5 \mathrm{~mm})$ são expostos por seis semanas ao fungo apodrecedor.

O método fornece resultados de perda de massa comparáveis aqueles obtidos por meio do método tradicional da norma BS 838:61, atualmente norma européia EN-113:80.

Blankenhorn et al. (1980) utilizaram, em ensaio acelerado para avaliação do poder calorífico de madeira deteriorada por fungos, corpos-de- 
prova de cerne, com dimensões de $43 \times 2 \times 2 \mathrm{~mm}$, colocados sobre culturas puras de fungos apodrecedores crescendo em placas de Petri contendo meio de cultura ágar-malte.

De acordo com os autores este ensaio acelerado teria as seguintes vantagens em relação ao "soil-block" tradicional: a) penetração mais regular das hifas dos fungos nos corpos-de-prova devido às suas menores dimensões, resultando em uma degradação mais uniforme; b) redução, aproximadamente pela metade, do tempo de exposição aos fungos normalmente requerido pelo procedimento do método "soil-block" (de 16 para 8 semanas); c) possibilidade de manipular, de forma conveniente, muitas réplicas durante o curso do experimento; d) degradação mais uniforme de todas as réplicas, sujeitas às mesmas condições de micro-ambiente, dentro de cada placa de Petri.

Fojutowsky \& Zielinski (1986), com o objetivo de abreviar o tempo de exposição aos fungos, compararam dois diferentes métodos de ensaio para avaliação da eficiência de produtos fungicidas. Um deles, o método "agar-block", tradicionalmente utilizado na Polônia, baseia-se na norma polonesa PN-76/C-04903, atualmente norma européia EN-113-80. O outro método utiliza corpos-de-prova de cerne menores, com dimensōes de $50 \times 15 \times 8 \mathrm{~mm}$, com a maior dimensão paralela à grã da madeira, depositados em frascos contendo um meio de cultura especial, composto por substâncias que estimulam a atividade enzimática dos fungos, tais como, sais minerais (macro e micro-elementos) e ácidos orgânicos.

Para o método PN-76/C-04903, o tempo de exposição aos fungos foi de aproximadamente 13 semanas (exatamente 90 dias); para 0 
segundo método, de apenas 4 semanas ( 28 dias), significando portanto, uma considerável redução.

Para ambos os métodos os autores utilizaram corpos-de-prova de Pinus silvestris L. sob a ação do fungo Coniophora puteana (Fr.) Karst, responsável por uma podridão parda na madeira. A preparação dos corpos-deprova, incluindo a impregnação com os produtos fungicidas, as condições de temperatura, de condicionamento e de umidade foram as mesmas para ambos os métodos.

Segundo os autores, para os corpos-de-prova controle não impregnados com produtos fungicidas, a perda de massa média atingiu, após 4 semanas de exposição pelo método acelerado, valores de 2 a $4 \%$ mais altos do que aquela obtida segundo o método PN-76/C-04903, após 13 semanas de exposição. Os autores não comentam quanto ao efeito da redução das dimensões dos corpos-de-prova na obtenção de resultados em menor espaço de tempo. 


\section{MATERIAL E MÉTODOS}

Dois diferentes métodos de ensaios acelerados para avaliação da resistência natural de madeiras ao apodrecimento foram comparados neste estudo.

0 primeiro deles, conhecido internacionalmente como "soilblock", teve como base a norma americana ASTM D-2017 "Standard Method for Accelerated Laboratory Test of Natural Decay Resistance of Woods".

0 segundo, método alternativo aqui denominado "mini-agarblock", foi adaptado a partir de descriçōes feitas por Blankenhorn et al. (1980), Bravery (1978) e Fojutowsky e Zielinski (1986).

Para ambos os métodos foram utilizadas as mesmas espécies de madeira e a mesma espécie de fungo apodrecedor.

\subsection{Espécies de madeira e corpos-de-prova}

Conforme apresentado no quadro a seguir, foram selecionadas cinco espécies de madeira, com diferentes características quanto à durabilidade natural.

\begin{tabular}{|c|c|c|}
\hline NOME POPULAR & NOME CIENTIFICO & FAMILIA \\
\hline aroeira & Astronium sp & Anacardiaceae \\
angico-preto & Anadenanthera sp & Mimosaceae \\
jatobá & Hymenaea sp & Caesalpinaceae \\
peroba-rosa & Aspidosperma polyneuron & Apocynaceae \\
pinho-do-paraná & Araucaria angustifolia & Araucariaceae \\
\hline
\end{tabular}


A madeira de aroeira é considerada na prática como a de mais alta resistência ao apodrecimento (Manieri \& Chimelo, 1985) e nos ensaios laboratoriais, de acordo com o método "soil-block", foi classificada como altamente resistente (Lepage, 1983).

A madeira de angico-preto, segundo observaçōes práticas nas zonas de ocorrência da espécie, é considerada de alta resistência ao apodrecimento (Manieri \& Chimelo, 1985), e nos ensaios laboratoriais, conforme o método "soil-block", demonstrou ser altamente resistente ao apodrecimento (Cavalcante et al., 1985).

A madeira de jatobá, em ensaios de laboratório, foi classificada como de resistência média a alta ao ataque de organismos xilófagos (Manieri \& Chimelo, 1985) e altamente resistente ao apodrecimento, com desempenho moderado em ensaios de campo (Cavalcante et al., 1985).

A madeira de peroba-rosa, em ensaios de laboratório, foi classificada como de baixa resistência ao ataque de organismos xilófagos (Manieri \& Chimelo, 1985).

A madeira de pinho-do-paraná demonstrou ter baixa resistência natural ao apodrecimento em ensaios laboratoriais (Cavalcante et al., 1985 e Manieri \& Chimelo, 1985).

Para as madeiras de folhosas, apenas o cerne foi utilizado nos ensaios, na medida em que todo alburno é considerado não durável. As amostras de madeira foram obtidas e identificadas no Laboratório de Anatomia e Identificação das Madeiras da Divisão de Produtos Florestais do Instituto de Pesquisas Tecnológicas do Estado de São Paulo - IPT. Todos os corpos-deprova foram retirados da mesma peça de madeira. 
Para o método "soil-block", foram utilizados corpos-de-prova de madeira com dimensões de $25 \times 25 \times 9 \mathrm{~mm}$, a menor dimensão paralela à grã.

Para o método "mini-agar-block", foram utilizados corpos-deprova de madeira com dimensões de $8 \times 8 \times 3 \mathrm{~mm}$, a menor dimensão também paralela à grã.

\subsection{Espécie de fungo}

Dentre as possíveis espécies de fungos adequadas para ensaios de apodrecimento acelerado, optou-se pela utilização do Gloeophyllum trabeum, cultura "American Type Culture Collection-ATCC" № 11539, responsável por uma podridão parda na madeira. Esta espécie é indicada para madeiras de coníferas e de folhosas (ASTM, 1986; CEN, 1980) e tem apresentado bons resultados em ensaios acelerados de apodrecimento (Amburgey, 1978; Amburgey, 1976; Highley, 1987; Monteiro et al., 1992 e Ruyooka \& Griffin, 1980).

\subsection{Procedimento para o método "soil-block"}

Seguindo o procedimento da norma americana ASTM D-2017 "Standard Method for Accelerated Laboratory Test of Natural Decay Resistance of Woods", corpos-de-prova das espécies de madeira selecionadas foram condicionados, em câmara climatizada, a uma temperatura de $26,7 \pm 1,1^{\circ} \mathrm{C}$ e umidade relativa de $70 \pm 4 \%$, até massa constante. A seguir, a massa inicial (Mi) de cada corpo-de-prova foi determinada, com precisão de $\pm 0,0001 \mathrm{~g}$, 
sendo esterilizados por 20 minutos em autoclave, a uma temperatura de $120^{\circ} \mathrm{C}$, no interior de frascos de vidro fechados.

Paralelamente foram preparados frascos de cultura, contendo solo com pH 5 e capacidade de retenção de água do solo (C.R.A.S.) de $72 \%$. A umidade deste solo foi ajustada para $150 \%$ da C.R.A.S. Foi acrescentado a cada frasco, sobre o solo úmido, um suporte de madeira de Pinus sp, susceptível ao apodrecimento.

Os frascos de cultura foram esterilizados em autoclave, a $120^{\circ} \mathrm{C}$, durante 30 minutos, por 3 vezes, com um intervalo de tempo entre cada esterilização de aproximadamente 12 horas. Após resfriamento, transferiu-se para o suporte de madeira de cada frasco de cultura um inóculo do Gloeophyllum trabeum.

Catorze dias após a transferência do fungo para os frascos de cultura e de sua incubação a uma temperatura de $26,7 \pm 1,1^{\circ} \mathrm{C}$ e umidade relativa de $70 \pm 4 \%$, os corpos-de-prova de madeira esterilizados foram colocados sobre o suporte de Pinus sp, em número de dois por frasco. Estes foram mantidos em câmara climatizada sob as mesmas condições de temperatura e umidade relativa, durante 14 semanas. Passado este período de incubação, os corpos-de-prova foram removidos dos frascos, limpos sob água corrente, condicionados até massa constante e pesados, para obtenção de sua massa final (Mf), sob as mesmas condições iniciais.

A avaliação da deterioração de cada corpo-de-prova foi feita por meio da determinação da perda de massa causada pelo fungo. Este valor, expresso em porcentagem, foi calculado de acordo com a seguinte fórmula:

$$
\text { [(Mi - Mf)/Mi] x } 100 .
$$




\subsection{Procedimento para o método "mini-agar-block"}

No método alternativo "mini-agar-block", adaptado a partir de descriçōes feitas por Blankenhorn et al. (1980), Bravery (1978) e Fojutowsky e Zielinski (1986), os corpos-de-prova foram divididos em 4 grupos ou tratamentos, conforme mostra a Figura 1.

No Tratamento I, os corpos-de-prova de madeira foram condicionados em câmara climatizada, pesados para determinação de sua massa inicial (Mi) e esterilizados em autoclave, sob as mesmas condições empregadas para os corpos-de-prova do método "soil-block".

No Tratamento II, os corpos-de-prova de madeira foram condicionados em câmara climatizada, pesados para determinação de sua massa inicial (Mi) e esterilizados por radiação ionizante (raios gama, fonte Cobalto-60), na EMBRARAD, São Paulo.

Os corpos-de-prova dos tratamentos III e IV foram condicionados (secos) por 24 horas em estufa a uma temperatura de $105^{\circ} \mathrm{C} \mathrm{e}$ pesados para determinação de sua massa inicial (Mi). Os corpos-de-prova do Tratamento III foram esterilizados em autoclave por 20 minutos a uma temperatura de $120^{\circ} \mathrm{C}$ e os do Tratamento IV foram esterilizados por radiação ionizante.

Paralelamente foram preparadas placas de Petri contendo meio de cultura composto por malte a $2 \%$ em ágar (MA2), sendo que cada uma foi inoculada com o Gloeophyllum trabeum. 
Seis dias após a inoculação das placas, os corpos-de-prova de madeira esterilizados foram colocados nas placas de Petri, em número de 4 por placa, em contato direto com o meio de cultura, na zona limite de crescimento do fungo. As placas foram seladas com uma fita adesiva semi-permeável, para evitar contaminação por ácaros, fungos oportunistas e bactérias, e incubadas em câmara climatizada a uma temperatura de $26,7 \pm 1^{\circ} \mathrm{C}$ e umidade relativa de $70 \pm 5 \%$, durante 8 semanas. Os corpos-de-prova foram então removidos das placas de Petri e limpos sob água corrente. Em função do tratamento recebido antes da inoculação do fungo, os corpos-de-prova de madeira foram secos em estufa ou condicionados em câmara climatizada, sendo pesados para determinação de sua massa final (Mf).

A avaliação da deterioração dos corpos-de-prova foi feita, como para o método "soil-block", por meio da determinação da perda de massa, expressa em porcentagem, devida à atividade da espécie de fungo. 


\section{CONDICIONAMENTO}

\section{ESTERILIZAÇÃO}

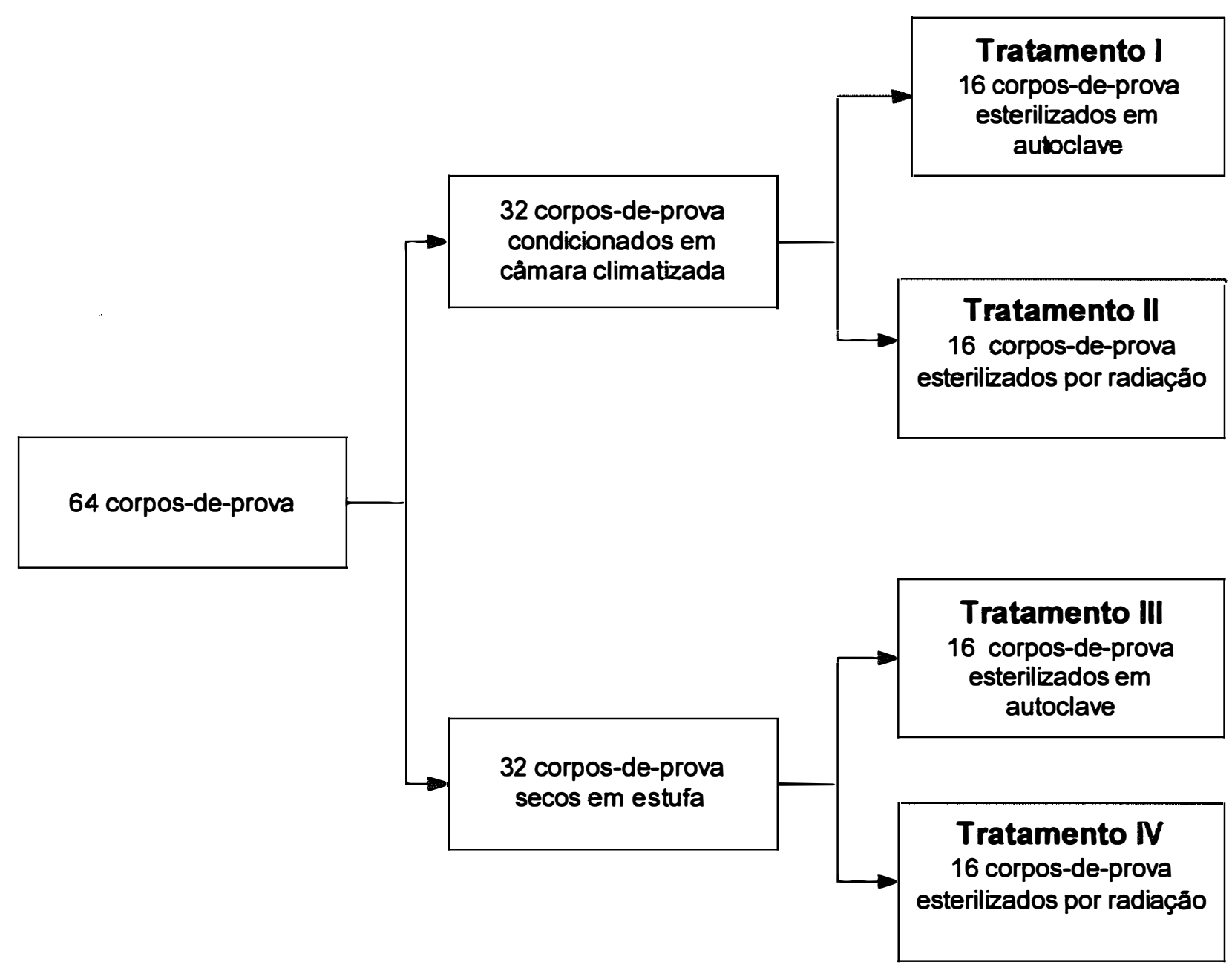

Figura 1 - Distribuição dos corpos-de-prova do método "mini-agar-block", por grupo ou tratamento. 


\subsection{Análises estatísticas}

Os resultados de perda de massa dos corpos-de-prova de madeira, expressos em porcentagem, obtidos para os 2 métodos, foram analisados estatisticamente, utilizando-se o aplicativo Statistica (StatSoft, Inc., 1995).

Foram realizadas análises estatísticas, ao nível de significância ( $\alpha$ ) de $5 \%$. Optou-se pela análise de variância paramétrica, particularmente robusta com respeito à não normalidade e heterogeneidade de variâncias quando os tratamentos são estimados utilizando-se igual número de observações - experimentos balanceados - $\left(\right.$ Box $^{7}$, citado por Underwood, 1981).

\subsubsection{Análises para comparação da durabilidade natural das espécies de madeira nos 2 métodos}

Para os 2 métodos ("soil-block" e "mini-agar-block" Tratamento I), os resultados obtidos foram submetidos às seguintes análises:

a) análise de variância com uma classificação, 5 tratamentos, ou seja, 5 espécies de madeira com diferentes graus de durabilidade natural; e 16 observações por tratamento;

b) teste de comparação múltipla de médias de Tukey ("Tukey honest significant difference test").

\footnotetext{
${ }^{7}$ BOX, G.E.P. Biometrika, v. 40, p. 318-335, 1953.
} 


\title{
3.5.2 Análises para verificar a influência dos fatores condicionamento e esterilização nos quatro tratamentos do método "mini-agar-block"
}

\author{
Para verificar a influência dos fatores condicionamento e \\ esterilização nos resultados obtidos por meio do método "mini-agar-block", \\ foram utilizadas as seguintes análises: \\ a) análise de variância fatorial em um experimento aleatório \\ com 3 fatores: espécie de madeira, com 5 niveis (aroeira, \\ angico-preto, jatobá, peroba-rosa, pinho-do-paraná); tipo de \\ condicionamento, com 2 niveis (corpos-de-prova \\ climatizados, corpos-de-prova secos em estufa); e tipo de \\ esterilização, com 2 níveis (em autoclave, por radiação); e \\ 16 observações por tratamento; \\ b) teste de comparação múltipla de médias de Tukey ("Tukey \\ honest significant difference test").
}




\section{RESULTADOS}

As Tabelas 1 e 2 apresentam para os métodos "soil-block" e "mini-agar-block" - Tratamento I, as médias $(x)$ de perda de massa, expressas em porcentagem, obtidas para os corpos-de-prova, das 5 espécies de madeira, expostos ao fungo Gloeophyllum trabeum. A Figura 2 representa graficamente estes valores de média.

Valores de dispersão como valor máximo (Máx.), valor mínimo (Mín.) e coeficiente de variação (C.V.), também constam das Tabelas 1 e 2.

O detalhamento destes resultados encontra-se nas Tabelas 5 a 9 do Anexos A e Tabelas 10 a 14 do Anexo B.

Tabela 1. Método "soil-block" - resultados de perda de massa.

\begin{tabular}{ccccc}
\hline madeira & $\mathbf{x}(\%)$ & Máx. (\%) & Mín. (\%) & C.V. (\%) \\
\hline aroeira & 1,85 & 2,03 & 1,71 & 5,14 \\
angico-preto & 1,43 & 1,78 & 0,76 & 17,48 \\
jatobá & 1,07 & 1,50 & $-0,23$ & 36,66 \\
peroba-rosa & 2,09 & 2,82 & 0,75 & 30,63 \\
pinho-do-paraná & 14,42 & 19,54 & 8,28 & 25,09 \\
\hline
\end{tabular}


Tabela 2. "Mini-agar-block" -Tratamento I - resultados de perda de massa.

\begin{tabular}{ccccc}
\hline madeira & $\mathbf{x}(\%)$ & Máx. (\%) & Mín. (\%) & C.V. (\%) \\
\hline aroeira & 3,94 & 5,03 & 3,18 & 10,58 \\
angico-preto & 4,24 & 4,98 & 3,58 & 8,56 \\
jatobá & 3,40 & 5,15 & 2,74 & 16,47 \\
peroba-rosa & 3,82 & 5,08 & 2,96 & 18,06 \\
pinho-do-paraná & 24,91 & 45,51 & 4,30 & 49,62 \\
\hline
\end{tabular}

Pode-se observar na Figura 2 que os valores médios obtidos para o método "mini-agar-block" foram sempre maiores do que aqueles apresentados pelos corpos-de-prova do método "soil-block". Para o método "soil-block" todas as espécies, exceto pinho-do-paraná, apresentaram valores médios de perda de massa, expressos em porcentagem, abaixo de $3 \%$. Para o método "mini-agar-block" os valores médios para todas as espécies, exceto pinho-do-paraná, situam-se entre 3 e 6 \%. 


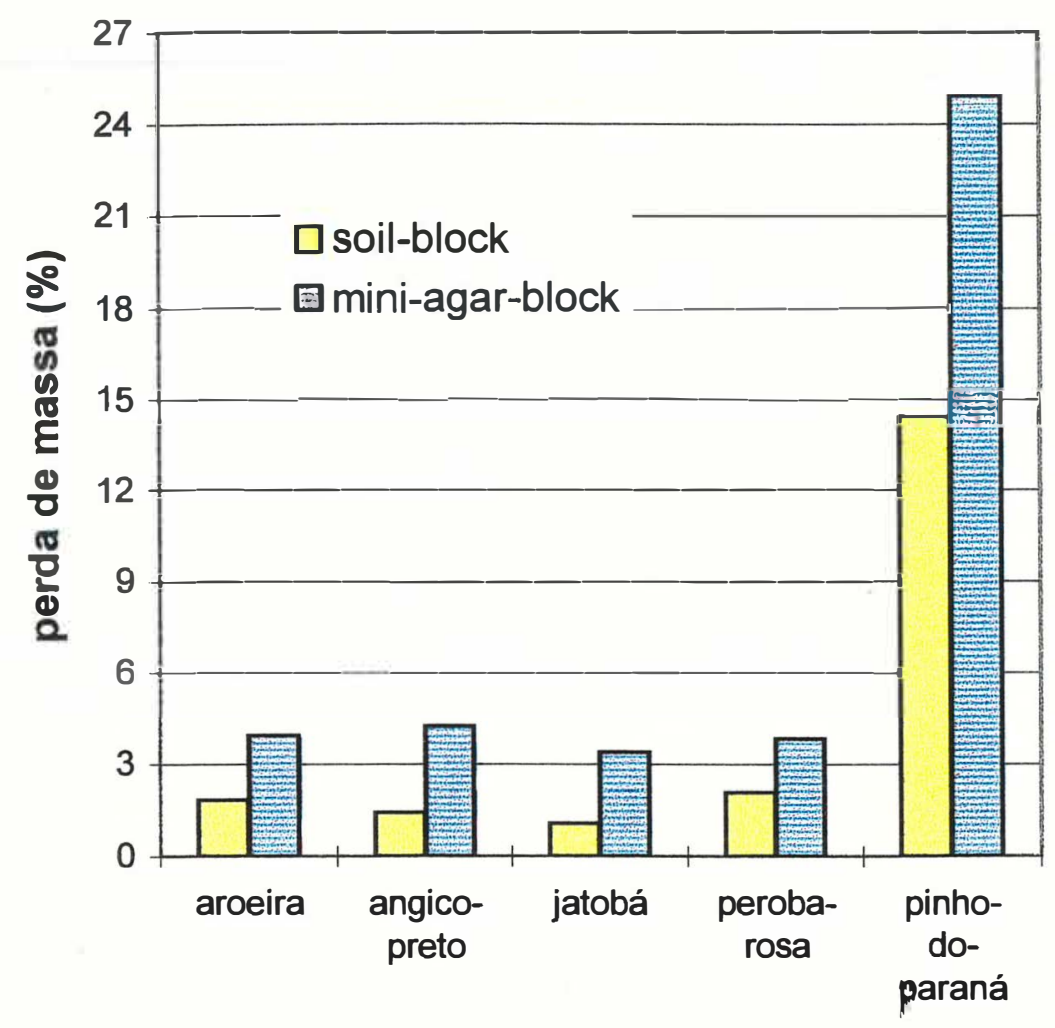

Figura 2 - Valores médios de perda de massa, expressos em porcentagem, para os métodos "soil-block" e "mini-agar-block" - Tratamento I. 
A Tabela 3 apresenta as médias $(x)$ de perda de massa, expressas em porcentagem, obtidas para os corpos-de-prova das 5 espécies de madeira, submetidos aos 4 diferentes tratamentos quanto ao tipo de condicionamento e tipo de esterilização, e expostos ao fungo Gloeophyllum trabeum de acordo com o método "mini-agar-block". O detalhamento destes resultados encontra-se nas Tabelas 9 a 14 do Anexo B, Tabelas 15 a 19 do Anexo C, Tabelas 20 a 24 do Anexo D e Tabelas 25 a 29 do Anexo E. A Figura 3 representa graficamente estes valores.

Valores de dispersão como valor máximo (Máx.), valor mínimo (Mín.) e coeficiente de variação (C.V.), também constam da Tabela 3.

Tabela 3. Método "mini-agar-block" - resultados obtidos para os diversos tratamentos.

\begin{tabular}{cccccc}
\hline madeira & tratamento & x $(\%)$ & Máx. (\%) & Mín. (\%) & C.V. (\%) \\
\hline \multirow{2}{*}{ aroeira } & I & 3,94 & 5,03 & 3,18 & 10,58 \\
& II & 1,13 & 2,25 & 0,42 & 44,73 \\
& III & 0,96 & 1,20 & 0,74 & 14,28 \\
& IV & 1,62 & 2,41 & 1,25 & 18,93 \\
angico-preto & I & 4,24 & 4,98 & 3,58 & 8,56 \\
& II & 1,54 & 2,75 & 0,15 & 44,21 \\
& III & 1,52 & 2,22 & 1,09 & 19,17 \\
& IV & 2,20 & 2,74 & 1,77 & 14,10 \\
jatobá & I & 3,40 & 5,15 & 2,74 & 16,47 \\
& II & 0,56 & 1,27 & 0,04 & 58,95 \\
& III & 1,85 & 2,78 & 1,41 & 19,15 \\
& IV & 2,14 & 4,11 & 1,11 & 33,67 \\
peroba-rosa & I & 3,82 & 5,08 & 2,96 & 18,06 \\
& II & 0,63 & 2,34 & $-0,15$ & 114,64 \\
& III & 2,69 & 4,36 & 1,82 & 27,15 \\
& IV & 2,42 & 4,24 & 1,35 & 31,69 \\
& I & 24,91 & 45,51 & 4,30 & 49,62 \\
pinho-do-paraná & II & 13,82 & 31,78 & 1,54 & 53,70 \\
& III & 18,27 & 48,27 & 2,95 & 81,65 \\
& IV & 27,42 & 47,65 & 2,91 & 54,21 \\
\hline
\end{tabular}




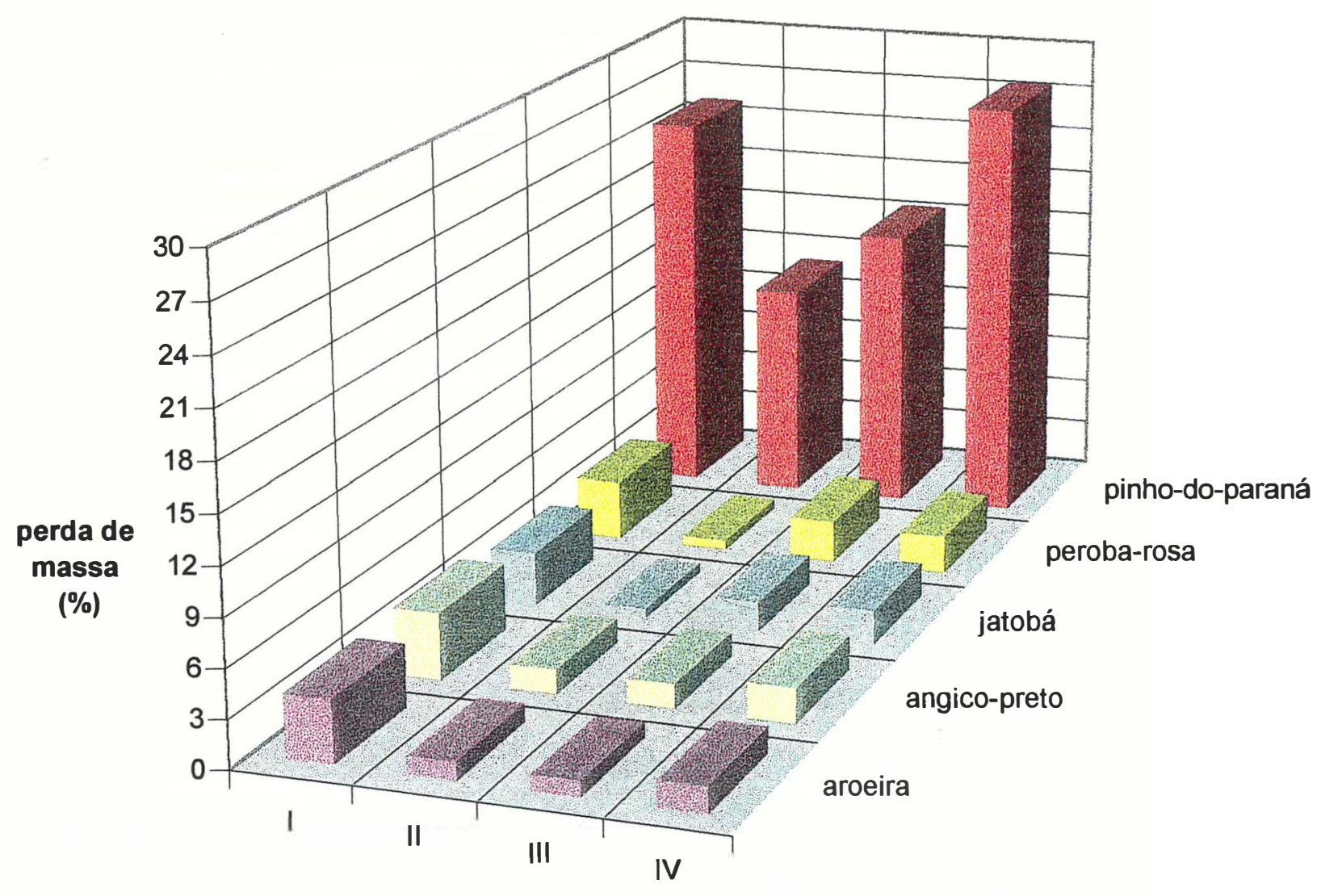

tratamentos

Figura 3 - Valores médios de perda de massa, expressos em porcentagem, para os quatro tratamentos do método "mini-agar-block". 


\subsection{Análises estatísticas}

\subsubsection{Comparação da durabilidade natural das espécies de madeira nos dois métodos}

Para os métodos "soil-block" e "mini-agar-block" - Tratamento I, as análises de variância foram significantes $(p=0,0000)$, ou seja, há evidências ao nível de $5 \%$ de significância de que pelo menos 1 par de médias difere. (Apêndices 1 e 2).

Os testes de Tukey de comparação múltipla de médias (Apêndices 1 e 2), permitiram, para ambos os métodos, as seguintes conclusões:

a) as médias de perda de massa das espécies de madeira aroeira, angicopreto, jatobá e peroba-rosa diferem significativamente da espécie pinho-doparaná, sendo que esta última apresenta a maior média de perda de massa;

b) as médias de perda de massa das espécies de madeira aroeira, angicopreto, jatobá e peroba-rosa não diferem significativamente entre si.

\subsubsection{Influência dos fatores condicionamento e esterilização nos quatro tratamentos do método "mini-agar-block"}

Para os diferentes tratamentos do método "mini-agar-block" a análise de variância fatorial detectou diferença significativa para a interação espécie de madeira $x$ tipo de condicionamento $x$ tipo de esterilização (Apêndice 3). 
O teste de Tukey (Apêndice 3 ) de comparação múltipla de médias permitiu concluir que:

a) as médias de perda de massa das espécies de madeira aroeira, angicopreto, jatobá e peroba-rosa não diferem significativamente entre si independente do tipo de condicionamento e esterilização empregados;

b) as médias de perda de massa das espécies de madeira aroeira, angicopreto, jatobá e peroba-rosa diferem significativamente da espécie de madeira pinho-do-paraná, independente do tipo de condicionamento e esterilização empregados;

c) a Tabela 4 apresenta, de forma resumida, as conclusões do teste de comparação múltipla de médias para a espécie de madeira pinho-do-paraná, onde os resultados médios de perda de massa para os quatro tratamentos são apresentados em ordem crescente de valores:

Tabela 4. Comparação dos tratamentos para pinho-do-paraná.

\begin{tabular}{ccccc}
\hline tratamento & $\times(\%)$ & \multicolumn{2}{c}{ comparaçåo * } \\
II (câmara, radiação) & 13,82 & a & & \\
III (estufa, autoclave) & 18,27 & a & b & \\
I (câmara, autoclave) & 24,91 & & b & C \\
IV (estufa, radiação) & 27,42 & & & c \\
\hline
\end{tabular}

* letras iguais representam valores significativamente iguais; letras diferentes representam valores significativamente diferentes.

d) média de perda de massa dos corpos-de-prova condicionados em câmara climatizada e esterilizados por radiação não difere significativamente da média dos corpos-de-prova secos em estufa e esterilizados em autoclave; 
e) a média de perda de massa dos corpos-de-prova secos em estufa e esterilizados em autoclave não difere significativamente das médias dos corpos-de-prova condicionados em câmara e esterilizados em autoclave;

f) a média de perda de massa dos corpos-de-prova condicionados em câmara climatizada e esterilizados em autoclave não difere significativamente das médias dos corpos-de-prova secos em estufa e esterilizados por radiação;

g) a média de perda de massa dos corpos-de-prova condicionados em câmara climatizada e esterilizados por radiação difere significativamente da média dos corpos-de-prova condicionados em câmara climatizada e esterilizados em autoclave, sendo que estes últimos apresentam a maior média de perda de massa;

h) a média de perda de massa dos corpos-de-prova condicionados em câmara climatizada e esterilizados por radiação difere significativamente da média dos corpos-de-prova secos em estufa e esterilizados por radiação, sendo que estes últimos apresentam a maior média de perda de massa;

i) a média dos corpos-de-prova secos em estufa e esterilizados em autoclave difere significativamente dos corpos-de-prova secos em estufa e esterilizados por radiação, sendo que estes últimos apresentam a maior média de perda de massa. 


\section{DISCUSSÃO}

\subsection{Comparação da durabilidade natural das espécies de madeira nos dois métodos}

No presente estudo, verificou-se que a redução nas dimensões dos corpos-de-prova teve um efeito favorável na aceleração na taxa de apodrecimento da madeira. Realmente, para todas as espécies de madeira submetidas aos ensaios, as perdas de massa obtidas nas oito semanas do método "mini-agar-block" foram maiores do que aquelas obtidas no método "soil-block" em 14 semanas de exposição. Bravery (1978), em estudo para avaliar a eficiência fungicida de produtos preservativos de madeira, parte do princípio de que a taxa de apodrecimento da madeira pode ser acelerada por meio da redução da massa dos corpos-de-prova.

Para ambos os métodos, os resultados da análise de variância e o teste de comparação múltipla de médias de Tukey indicaram os mesmos dois grupos, ou seja, destacaram as espécies de madeira aroeira, angico-preto, jatobá e peroba-rosa da espécie pinho-do-paraná. Dentro das limitações deste estudo, ambos os métodos classificaram as espécies de madeira em dois grupos distintos, compostos pelas mesmas espécies de madeira. 
Isto fornece uma indicação de que os métodos de ensaio, com pequenos ajustes no método alternativo, podem vir a ser equivalentes. Assim, o método alternativo, "mini-agar-block", parece promissor como possível substituto ao método "soil-block" para avaliação da durabilidade natural de madeiras.

Entretanto, o ataque do fungo Gloeophyllum trabeum não permitiu separar estatisticamente, em nenhum dos métodos, espécies de madeira com durabilidade natural tão diferentes quanto a aroeira e a perobarosa. Para todas as espécies de madeira de folhosas, ou seja, para aroeira, angico-preto, jatobá e peroba-rosa, as perdas de massa situaram-se sempre abaixo de $6 \%$, valor que situaria todas estas espécies de madeira na classe "altamente resistente" da norma ASTM D-2017.

Em ambos os métodos de ensaio, as perdas de massa observadas para a espécie de madeira pinho-do-paraná, utilizada como referência, foram bem menores do que as esperadas para uma espécie não durável.

A escolha do fungo Gloeophyllum trabeum foi apoiada na literatura e em experiência própria, adquirida no IPT, com a realização de ensaios laboratoriais de apodrecimento acelerado.

De acordo com a literatura, essa espécie é responsável pela deterioração da madeira em situações diversas, desde árvores em pé até estruturas de madeira em serviço, apresentando uma distribuição cosmopolita (Eaton \& Hale, 1993). Ocorre inclusive no Brasil (Milano et al., 1985), 
provocando um rápido apodrecimento tanto em madeiras de coníferas quanto de folhosas (Duncan \& Lombard ${ }^{8}$, citados por Eaton \& Hale, 1993).

Em ensaios de apodrecimento acelerado ("soil-block"), perdas de massa acima de $58 \%$ foram obtidas com este fungo, para espécies de madeira de baixa durabilidade natural como Acer rubrum L. (Highley, 1987) e Pinus spp (Eslyn ${ }^{9}$, citado por Eaton \& Hale, 1993).

Em ensaios "soil-block" realizados no IPT a espécie Gloeophyllum trabeum tem provocado médias de perda de massa superiores a $60 \%$ em madeira de Pinus spp, normalmente utilizada como referência de baixa durabilidade natural.

A norma européia EN 113 no entanto, indica para a espécie Gloeophyllum trabeum, um valor mínimo aceitável de perda de massa de $20 \%$, em 16 semanas, para alburno de "Scot pine".

Seja qual for o método de ensaio empregado, sugere-se acrescentar às espécies de fungos recomendadas pelo método "soil-block", espécies de fungos isoladas no Brasil, a partir de madeiras nativas em processo de deterioração.

Por outras razões, ou seja, pelos ensaios laboratoriais não produzirem resultados que permitam o estabelecimento de correlações válidas para a realidade de exposição às condições brasileiras, Lepage (1983), recomenda adaptações no método de ensaio "soil-block" às condições existentes em nosso país adotando-se, dentre outras medidas, espécies de fungos mais representativas da micota de nossas florestas nativas.

\footnotetext{
${ }^{8}$ DUNCAN, C.G., LOMBARD, F.F. Fungi associated with principal decays in wood products in United States, U.S. Forest Service Research Paper WO-4, Washington.

${ }^{9}$ ESLYN, W.E. Utility pole decay, part 4: growth-temperature relationships and decay capacities of eleven major utility pole decay fungi. Holzforschung, 40 (2), 69-77.
} 


\subsection{Influência dos fatores condicionamento e esterilização nos quatro tratamentos do método "mini-agar-block"}

Para as espécies de folhosas, ou seja, para aroeira, angicopreto, jatobá e peroba-rosa, o tipo de tratamento a que foram submetidos os corpos-de-prova não teve influência sobre os resultados obtidos.

Para a espécie de madeira pinho-do-paraná, as razões para as diferenças significativas obtidas entre os tratamentos não estão claras. Elas podem ser devidas à redução na dimensão dos corpos-de-prova que parece ter aumentado a variabilidade dos resultados de perda de massa obtidos (alto coeficiente de variação dentro do grupo de observações). Com freqüência, grandes diferenças na durabilidade natural podem ser esperadas, mesmo em peças de madeira retiradas da mesma árvore (BRE, 1969). Corpos-de-prova com dimensões menores seriam responsáveis por este aumento na variabilidade dos resultados, em um material heterogêneo como é a madeira $\left(\right.$ Watai $\left.^{10}\right)$.

Uma explicação plenamente satisfatória para os resultados obtidos só poderá ser conseguida com mais experimentação. Sugere-se um aumento do número de observações ou repetições por tratamento, e/ou uma seleção mais cuidadosa dos corpos-de-prova, com o objetivo de obter grupos mais homogêneos.

\footnotetext{
${ }^{10}$ Watai, L.T. Comunicação pessoal, 1997.
} 


\section{CONCLUSÕES}

O método de ensaio alternativo, "mini-agar-block", mostrou-se promissor e candidato à substituição do método de ensaio tradicional "soilblock", por ter classificado as espécies de madeira da mesma forma e ter permitido, em menor espaço de tempo, a obtenção de resultados de perda de massa maiores para todas as espécies de madeira ensaiadas. Além da redução do tempo de ensaio o "mini-agar-block" apresentou outras vantagens em relação ao "soil-block", como:

a) economia de espaço na câmara climática- 0 volume ocupado pelos recipientes (placas de Petri) do "mini-agar-block" foi muito menor do que aquele ocupado pelos recipientes (frascos com solo) do "soilblock"; além disso, em cada recipiente do "mini-agar-block" cabem até 8 corpos-de-prova, enquanto que, em cada recipiente do "soil-block" cabem apenas 2 corpos-de-prova;

b) maior facilidade na preparação do material para o ensaio e na manipulação dos corpos-de-prova;

c) menor volume de madeira a ser ensaiada.

$O$ ataque da espécie de fungo Gloeophyllum trabeum não permitiu separar estatisticamente, em nenhum dos métodos, espécies de madeira com durabilidade natural tão diferentes quanto a aroeira e a perobarosa. 


\section{Anexo A}

Método "soil-block" - resultados de perda de massa obtidos para as cinco espécies de madeira submetidas ao apodrecimento por Gloeophyllum trabeum 
Tabela 5. Método "soil-block" - resultados obtidos para aroeira (Astronium sp)

\begin{tabular}{ccccc}
\hline observação & Mi (g) & Mf $(\mathbf{g})$ & Mf-Mi (g) & perda de massa (\%) \\
\hline A1 & 5,3924 & 5,2879 & 0,1045 & 1,94 \\
A2 & 5,6715 & 5,5610 & 0,1105 & 1,95 \\
A3 & 5,4704 & 5,3684 & 0,1020 & 1,86 \\
A4 & 5,5556 & 5,4542 & 0,1014 & 1,83 \\
A5 & 5,6385 & 5,5320 & 0,1065 & 1,89 \\
A6 & 5,4363 & 5,3314 & 0,1049 & 1,93 \\
A7 & 5,6593 & 5,5589 & 0,1004 & 1,77 \\
A8 & 5,4246 & 5,3144 & 0,1102 & 2,03 \\
A9 & 5,6247 & 5,5206 & 0,1041 & 1,85 \\
A10 & 5,8624 & 5,7497 & 0,1127 & 1,92 \\
A11 & 5,4986 & 5,3990 & 0,0996 & 1,81 \\
A12 & 5,5436 & 5,4470 & 0,0966 & 1,74 \\
A13 & 5,7009 & 5,6034 & 0,0975 & 1,71 \\
A14 & 5,6735 & 5,5757 & 0,0978 & 1,72 \\
A15 & 5,8052 & 5,7053 & 0,0999 & 1,72 \\
A16 & 5,5895 & 5,4862 & 0,1033 & 1,85 \\
\hline
\end{tabular}

Tabela 6. Método "soil-block" - resultados obtidos para angico-preto (Anadenanthera sp)

\begin{tabular}{ccccc}
\hline observação & Mi (g) & Mf (g) & Mf-Mi (g) & perda de massa (\%) \\
\hline B1 & 6,9328 & 6,8231 & 0,1097 & 1,58 \\
B2 & 6,8510 & 6,7508 & 0,1002 & 1,46 \\
B3 & 7,1020 & 6,9897 & 0,1123 & 1,58 \\
B4 & 6,8234 & 6,7312 & 0,0922 & 1,35 \\
B5 & 6,3950 & 6,3115 & 0,0835 & 1,31 \\
B6 & 6,9879 & 6,8880 & 0,0999 & 1,43 \\
B7 & 6,3643 & 6,2721 & 0,0922 & 1,45 \\
B8 & 6,5630 & 6,4461 & 0,1169 & 1,78 \\
B9 & 6,6721 & 6,5742 & 0,0979 & 1,47 \\
B10 & 6,4174 & 6,3688 & 0,0486 & 0,76 \\
B11 & 6,6917 & 6,6005 & 0,0912 & 1,36 \\
B12 & 6,5517 & 6,4789 & 0,0728 & 1,11 \\
B13 & 6,6131 & 6,5105 & 0,1026 & 1,55 \\
B14 & 6,1592 & 6,0824 & 0,0768 & 1,25 \\
B15 & 6,9249 & 6,8069 & 0,1180 & 1,70 \\
B16 & 6,5660 & 6,4565 & 0,1095 & 1,67 \\
\hline
\end{tabular}


Tabela 7. Método "soil-block" - resultados obtidos para jatobá (Hymenaea sp)

\begin{tabular}{ccccc}
\hline observação & Mi (g) & Mf $(\mathbf{g})$ & Mf-Mi (g) & perda de massa (\%) \\
\hline C1 & 5,5834 & 5,4996 & 0,0838 & 1,50 \\
C2 & 5,5840 & 5,5237 & 0,0603 & 1,08 \\
C3 & 5,6695 & 5,6056 & 0,0639 & 1,13 \\
C4 & 5,5149 & 5,4696 & 0,0453 & 0,82 \\
C5 & 5,6353 & 5,5613 & 0,0740 & 1,31 \\
C6 & 5,5120 & 5,4395 & 0,0725 & 1,32 \\
C7 & 5,6316 & 5,5545 & 0,0771 & 1,37 \\
C8 & 5,5303 & 5,4574 & 0,0729 & 1,32 \\
C9 & 5,6405 & 5,6532 & $-0,0127$ & $-0,23$ \\
C10 & 5,6234 & 5,5615 & 0,0619 & 1,10 \\
C11 & 5,7309 & 5,6779 & 0,0530 & 0,92 \\
C12 & 5,6118 & 5,5585 & 0,0533 & 0,95 \\
C13 & 5,5660 & 5,5122 & 0,0538 & 0,97 \\
C14 & 5,4616 & 5,4011 & 0,0605 & 1,11 \\
C15 & 5,5677 & 5,5016 & 0,0661 & 1,19 \\
C16 & 5,4939 & 5,4215 & 0,0724 & 1,32 \\
\hline
\end{tabular}

Tabela 8. Método "soil-block" - resultados obtidos para peroba-rosa (Aspidosperma polyneuron)

\begin{tabular}{ccccc}
\hline observação & Mi (g) & Mf $(\mathbf{g})$ & Mf-Mi (g) & perda de massa (\%) \\
\hline D1 & 4,8583 & 4,7544 & 0,1039 & 2,14 \\
D2 & 4,8273 & 4,7066 & 0,1207 & 2,50 \\
D3 & 4,9785 & 4,8379 & 0,1406 & 2,82 \\
D4 & 5,0115 & 4,8836 & 0,1279 & 2,55 \\
D5 & 4,9548 & 4,8764 & 0,0784 & 1,58 \\
D6 & 4,7218 & 4,6210 & 0,1008 & 2,13 \\
D7 & 4,8733 & 4,7628 & 0,1105 & 2,27 \\
D8 & 4,9564 & 4,8241 & 0,1323 & 2,67 \\
D9 & 4,8066 & 4,7071 & 0,0995 & 2,07 \\
D10 & 4,7479 & 4,6390 & 0,1089 & 2,29 \\
D11 & 4,9800 & 4,9007 & 0,0793 & 1,59 \\
D12 & 4,8819 & 4,7470 & 0,1349 & 2,76 \\
D13 & 4,7896 & 4,7538 & 0,0358 & 0,75 \\
D14 & 4,8113 & 4,7727 & 0,0386 & 0,80 \\
D15 & 4,9659 & 4,8754 & 0,0905 & 1,82 \\
D16 & 4,9999 & 4,8675 & 0,1324 & 2,65 \\
\hline
\end{tabular}


Tabela 9. Método "soil-block" - resultados obtidos para pinho-do-paraná (Araucaria angustifolia)

\begin{tabular}{ccccc}
\hline observaçảo & Mi (g) & Mf (g) & Mf-Mi (g) & perda de massa (\%) \\
\hline E1 & 3,7878 & 3,0824 & 0,7054 & 18,62 \\
E2 & 3,8482 & 3,2079 & 0,6403 & 16,64 \\
E3 & 3,7551 & 3,4279 & 0,3272 & 8,71 \\
E4 & 4,0150 & 3,4244 & 0,5906 & 14,71 \\
E5 & 4,0593 & 3,2660 & 0,7933 & 19,54 \\
E6 & 4,0609 & 3,3319 & 0,7290 & 17,95 \\
E7 & 3,7309 & 3,1191 & 0,6118 & 16,40 \\
E8 & 3,8121 & 3,4591 & 0,3530 & 9,26 \\
E9 & 3,8348 & 3,5174 & 0,3174 & 8,28 \\
E10 & 4,0153 & 3,5383 & 0,4770 & 11,88 \\
E11 & 3,8225 & 3,3591 & 0,4634 & 12,12 \\
E12 & 3,8373 & 3,2467 & 0,5906 & 15,39 \\
E13 & 3,8746 & 3,2973 & 0,5773 & 14,90 \\
E14 & 3,7725 & 3,3194 & 0,4531 & 12,01 \\
E15 & 3,8447 & 3,2025 & 0,6422 & 16,70 \\
E16 & 3,7842 & 3,1179 & 0,6663 & 17,61 \\
\hline
\end{tabular}




\section{Anexo B}

Tratamento I do método "mini-agar-block" - resultados de perda de massa obtidos para as cinco espécies de madeira submetidas ao apodrecimento por Gloeophyllum trabeum 
Tabela 10. Tratamento I do método "mini-agar-block" - resultados obtidos para aroeira (Astronium sp)

\begin{tabular}{ccccc}
\hline observação & Mi (g) & Mf (g) & Mi-Mf (g) & perda de massa (\%) \\
\hline A17 & 0,3531 & 0,3391 & 0,0140 & 3,96 \\
A18 & 0,3378 & 0,3247 & 0,0131 & 3,88 \\
A19 & 0,3966 & 0,3818 & 0,0148 & 3,73 \\
A20 & 0,3673 & 0,3537 & 0,0136 & 3,70 \\
A21 & 0,3804 & 0,3650 & 0,0154 & 4,05 \\
A22 & 0,3650 & 0,3518 & 0,0132 & 3,62 \\
A23 & 0,3770 & 0,3650 & 0,0120 & 3,18 \\
A24 & 0,3622 & 0,3482 & 0,0140 & 3,87 \\
A25 & 0,3960 & 0,3761 & 0,0199 & 5,03 \\
A26 & 0,4204 & 0,4026 & 0,0178 & 4,23 \\
A27 & 0,3080 & 0,2955 & 0,0125 & 4,06 \\
A28 & 0,3460 & 0,3311 & 0,0149 & 4,31 \\
A29 & 0,3359 & 0,3244 & 0,0115 & 3,42 \\
A30 & 0,3025 & 0,2900 & 0,0125 & 4,13 \\
A31 & 0,3755 & 0,3615 & 0,0140 & 3,73 \\
A32 & 0,4163 & 0,3990 & 0,0173 & 4,16 \\
\hline
\end{tabular}

Tabela 11. Tratamento I do método "mini-agar-block" - resultados obtidos para angico-preto (Anadenanthera sp)

\begin{tabular}{ccccc}
\hline observação & Mi (g) & Mf (g) & Mi-Mf (g) & perda de massa (\%) \\
\hline B17 & 0,4254 & 0,4089 & 0,0165 & 3,88 \\
B18 & 0,3746 & 0,3585 & 0,0161 & 4,30 \\
B19 & 0,4191 & 0,4009 & 0,0182 & 4,34 \\
B20 & 0,3895 & 0,3741 & 0,0154 & 3,95 \\
B21 & 0,3426 & 0,3289 & 0,0137 & 4,00 \\
B22 & 0,4205 & 0,4033 & 0,0172 & 4,09 \\
B23 & 0,4003 & 0,3822 & 0,0181 & 4,52 \\
B24 & 0,3979 & 0,3801 & 0,0178 & 4,47 \\
B25 & 0,4228 & 0,4046 & 0,0182 & 4,30 \\
B26 & 0,3881 & 0,3717 & 0,0164 & 4,23 \\
B27 & 0,3878 & 0,3715 & 0,0163 & 4,20 \\
B28 & 0,3710 & 0,3551 & 0,0159 & 4,29 \\
B29 & 0,3914 & 0,3719 & 0,0195 & 4,98 \\
B30 & 0,3831 & 0,3685 & 0,0146 & 3,81 \\
B31 & 0,4120 & 0,3921 & 0,0199 & 4,83 \\
B32 & 0,3692 & 0,3560 & 0,0132 & 3,58 \\
\hline
\end{tabular}


Tabela 12. Tratamento I do método "mini-agar-block" - resultados obtidos para jatobá (Hymenaea sp)

\begin{tabular}{ccccc}
\hline observação & Mi (g) & Mf (g) & Mi-Mf (g) & perda de massa (\%) \\
\hline C17 & 0,2857 & 0,2752 & 0,0105 & 3,68 \\
C18 & 0,2772 & 0,2696 & 0,0076 & 2,74 \\
C19 & 0,2919 & 0,2823 & 0,0096 & 3,29 \\
C20 & 0,2912 & 0,2825 & 0,0087 & 2,99 \\
C21 & 0,2965 & 0,2858 & 0,0107 & 3,61 \\
C22 & 0,2859 & 0,2774 & 0,0085 & 2,97 \\
C23 & 0,3243 & 0,3076 & 0,0167 & 5,15 \\
C24 & 0,2719 & 0,2625 & 0,0094 & 3,46 \\
C25 & 0,2620 & 0,2524 & 0,0096 & 3,66 \\
C26 & 0,2823 & 0,2727 & 0,0096 & 3,40 \\
C27 & 0,2955 & 0,2869 & 0,0086 & 2,91 \\
C28 & 0,2865 & 0,2762 & 0,0103 & 3,60 \\
C29 & 0,2711 & 0,2630 & 0,0081 & 2,99 \\
C30 & 0,2855 & 0,2756 & 0,0099 & 3,47 \\
C31 & 0,2654 & 0,2562 & 0,0092 & 3,47 \\
C32 & 0,2897 & 0,2811 & 0,0086 & 2,97 \\
\hline
\end{tabular}

Tabela 13. Método "mini-agar-block" - resultados obtidos para peroba-rosa (Aspidosperma polyneuron)

\begin{tabular}{ccccc}
\hline observação & Mi (g) & Mf (g) & Mi-Mf (g) & perda de massa (\%) \\
\hline D17 & 0,2521 & 0,2436 & 0,0085 & 3,37 \\
D18 & 0,2570 & 0,2442 & 0,0128 & 4,98 \\
D19 & 0,2879 & 0,2763 & 0,0116 & 4,03 \\
D20 & 0,2725 & 0,2641 & 0,0084 & 3,08 \\
D21 & 0,2921 & 0,2802 & 0,0119 & 4,07 \\
D22 & 0,2913 & 0,2790 & 0,0123 & 4,22 \\
D23 & 0,2734 & 0,2653 & 0,0081 & 2,96 \\
D24 & 0,2940 & 0,2843 & 0,0097 & 3,30 \\
D25 & 0,2583 & 0,2489 & 0,0094 & 3,64 \\
D26 & 0,2911 & 0,2763 & 0,0148 & 5,08 \\
D27 & 0,2880 & 0,2739 & 0,0141 & 4,90 \\
D28 & 0,2995 & 0,2873 & 0,0122 & 4,07 \\
D29 & 0,2953 & 0,2845 & 0,0108 & 3,66 \\
D30 & 0,2844 & 0,2750 & 0,0094 & 3,31 \\
D31 & 0,2889 & 0,2792 & 0,0097 & 3,36 \\
D32 & 0,2626 & 0,2543 & 0,0083 & 3,16 \\
\hline
\end{tabular}


Tabela 14. Método "mini-agar-block" - resultados obtidos para pinho-do-paraná (Araucaria angustifolia)

\begin{tabular}{ccccc}
\hline observaçāo & Mi (g) & Mf (g) & Mi-Mf (g) & perda de massa (\%) \\
\hline E17 & 0,2254 & 0,2089 & 0,0165 & 7,32 \\
E18 & 0,2086 & 0,1506 & 0,0580 & 27,80 \\
E19 & 0,1771 & 0,0998 & 0,0773 & 43,65 \\
E20 & 0,2064 & 0,1707 & 0,0357 & 17,30 \\
E21 & 0,2146 & 0,1549 & 0,0597 & 27,82 \\
E22 & 0,2190 & 0,1672 & 0,0518 & 23,65 \\
E23 & 0,2115 & 0,1676 & 0,0439 & 20,76 \\
E24 & 0,2496 & 0,1529 & 0,0967 & 38,74 \\
E25 & 0,2143 & 0,1396 & 0,0747 & 34,86 \\
E26 & 0,1738 & 0,0947 & 0,0791 & 45,51 \\
E27 & 0,1952 & 0,1412 & 0,0540 & 27,66 \\
E28 & 0,2111 & 0,1548 & 0,0563 & 26,67 \\
E29 & 0,2022 & 0,1670 & 0,0352 & 17,41 \\
E30 & 0,2172 & 0,1560 & 0,0612 & 28,18 \\
E31 & 0,2102 & 0,1955 & 0,0147 & 6,99 \\
E32 & 0,2163 & 0,2070 & 0,0093 & 4,30 \\
\hline
\end{tabular}




\section{Anexo C}

Tratamento II do método "mini-agar-block" - resultados de perda de massa obtidos para as cinco espécies de madeira submetidas ao apodrecimento por Gloeophyllum trabeum 
Tabela 15. Tratamento II do método "mini-agar-block" - resultados obtidos para aroeira (Astronium sp)

\begin{tabular}{ccccc}
\hline observação & Mi (g) & Mf (g) & Mi-Mf (g) & perda de massa (\%) \\
\hline A1 & 0,3824 & 0,3803 & 0,0021 & 0,55 \\
A2 & 0,3745 & 0,3714 & 0,0031 & 0,83 \\
A3 & 0,3600 & 0,3568 & 0,0032 & 0,89 \\
A4 & 0,4243 & 0,4225 & 0,0018 & 0,42 \\
A5 & 0,4220 & 0,4160 & 0,0060 & 1,42 \\
A6 & 0,3858 & 0,3821 & 0,0037 & 0,96 \\
A7 & 0,3668 & 0,3632 & 0,0036 & 0,98 \\
A8 & 0,3777 & 0,3749 & 0,0028 & 0,74 \\
A9 & 0,3583 & 0,3506 & 0,0077 & 2,15 \\
A10 & 0,3800 & 0,3762 & 0,0038 & 1,00 \\
A11 & 0,3189 & 0,3157 & 0,0032 & 1,00 \\
A12 & 0,3877 & 0,3842 & 0,0035 & 0,90 \\
A13 & 0,3695 & 0,3612 & 0,0083 & 2,25 \\
A14 & 0,3606 & 0,3550 & 0,0056 & 1,55 \\
A15 & 0,3619 & 0,3575 & 0,0044 & 1,22 \\
A16 & 0,3905 & 0,3857 & 0,0048 & 1,23 \\
\hline
\end{tabular}

Tabela 16. Tratamento II do método "mini-agar-block" - resultados obtidos para angico-preto (Anadenanthera sp)

\begin{tabular}{ccccc}
\hline observação & Mi (g) & Mf (g) & Mi-Mf (g) & perda de massa (\%) \\
\hline B1 & 0,3762 & 0,3690 & 0,0072 & 1,91 \\
B2 & 0,3916 & 0,3841 & 0,0075 & 1,92 \\
B3 & 0,4008 & 0,3948 & 0,0060 & 1,50 \\
B4 & 0,3853 & 0,3777 & 0,0076 & 1,97 \\
B5 & 0,3956 & 0,3920 & 0,0036 & 0,91 \\
B6 & 0,3954 & 0,3948 & 0,0006 & 0,15 \\
B7 & 0,3900 & 0,3866 & 0,0034 & 0,87 \\
B8 & 0,3816 & 0,3749 & 0,0067 & 1,76 \\
B9 & 0,3946 & 0,3901 & 0,0045 & 1,14 \\
B10 & 0,3909 & 0,3825 & 0,0084 & 2,15 \\
B11 & 0,4174 & 0,4137 & 0,0037 & 0,89 \\
B12 & 0,3621 & 0,3571 & 0,0050 & 1,38 \\
B13 & 0,3966 & 0,3922 & 0,0044 & 1,11 \\
B14 & 0,3720 & 0,3656 & 0,0064 & 1,72 \\
B15 & 0,3926 & 0,3826 & 0,0100 & 2,55 \\
B16 & 0,3233 & 0,3144 & 0,0089 & 2,75 \\
\hline
\end{tabular}


Tabela 17. Tratamento II do método "mini-agar-block" - resultados obtidos para jatobá (Hymenaea sp)

\begin{tabular}{ccccc}
\hline observação & Mi (g) & Mf (g) & Mi-Mf (g) & perda de massa (\%) \\
\hline C1 & 0,283 & 0,282 & 0,001 & 0,46 \\
C2 & 0,298 & 0,296 & 0,002 & 0,67 \\
C3 & 0,277 & 0,276 & 0,001 & 0,29 \\
C4 & 0,279 & 0,277 & 0,002 & 0,68 \\
C5 & 0,338 & 0,335 & 0,003 & 0,89 \\
C6 & 0,332 & 0,331 & 0,001 & 0,15 \\
C7 & 0,301 & 0,300 & 0,001 & 0,20 \\
C8 & 0,298 & 0,297 & 0,001 & 0,20 \\
C9 & 0,298 & 0,296 & 0,002 & 0,80 \\
C10 & 0,306 & 0,304 & 0,002 & 0,65 \\
C11 & 0,284 & 0,284 & 0,000 & 0,04 \\
C12 & 0,328 & 0,326 & 0,002 & 0,52 \\
C13 & 0,297 & 0,295 & 0,002 & 0,57 \\
C14 & 0,291 & 0,288 & 0,004 & 1,27 \\
C15 & 0,296 & 0,294 & 0,002 & 0,67 \\
C16 & 0,296 & 0,293 & 0,003 & 0,95 \\
\hline
\end{tabular}

Tabela 18. Tratamento II do método "mini-agar-block" - resultados obtidos para peroba-rosa (Aspidosperma polyneuron)

\begin{tabular}{ccccc}
\hline observação & Mi (g) & Mf (g) & Mi-Mf (g) & perda de massa (\%) \\
\hline D1 & 0,2762 & 0,2751 & 0,0011 & 0,40 \\
D2 & 0,2729 & 0,2726 & 0,0003 & 0,11 \\
D3 & 0,2784 & 0,2785 & $-0,0001$ & $-0,04$ \\
D4 & 0,2965 & 0,2948 & 0,0017 & 0,57 \\
D5 & 0,2761 & 0,2755 & 0,0006 & 0,22 \\
D6 & 0,2786 & 0,2738 & 0,0048 & 1,72 \\
D7 & 0,2905 & 0,2866 & 0,0039 & 1,34 \\
D8 & 0,2808 & 0,2802 & 0,0006 & 0,21 \\
D9 & 0,2716 & 0,2695 & 0,0021 & 0,77 \\
D10 & 0,2700 & 0,2698 & 0,0002 & 0,07 \\
D11 & 0,2823 & 0,2796 & 0,0027 & 0,96 \\
D12 & 0,2742 & 0,2746 & $-0,0004$ & $-0,15$ \\
D13 & 0,2730 & 0,2693 & 0,0037 & 1,36 \\
D14 & 0,2928 & 0,2924 & 0,0004 & 0,14 \\
D15 & 0,2865 & 0,2798 & 0,0067 & 2,34 \\
D16 & 0,2850 & 0,2848 & 0,0002 & 0,07 \\
\hline
\end{tabular}


Tabela 19. Tratamento II do método "mini-agar-block" - resultados obtidos para pinho-do-paraná (Araucaria angustifolia)

\begin{tabular}{ccccc}
\hline observaçăo & Mi (g) & Mf (g) & Mi-Mf (g) & perda de massa (\%) \\
\hline E1 & 0,2069 & 0,1706 & 0,0363 & 17,54 \\
E2 & 0,2022 & 0,1904 & 0,0118 & 5,84 \\
E3 & 0,1691 & 0,1665 & 0,0026 & 1,54 \\
E4 & 0,2379 & 0,1623 & 0,0756 & 31,78 \\
E5 & 0,2075 & 0,1820 & 0,0255 & 12,29 \\
E6 & 0,2158 & 0,1916 & 0,0242 & 11,21 \\
E7 & 0,2092 & 0,1845 & 0,0247 & 11,81 \\
E8 & 0,1956 & 0,1583 & 0,0373 & 19,07 \\
E9 & 0,2362 & 0,1834 & 0,0528 & 22,35 \\
E10 & 0,2024 & 0,1652 & 0,0372 & 18,38 \\
E11 & 0,2178 & 0,1978 & 0,0200 & 9,18 \\
E12 & 0,2043 & 0,1615 & 0,0428 & 20,95 \\
E13 & 0,2104 & 0,1894 & 0,0210 & 9,98 \\
E14 & 0,2054 & 0,1881 & 0,0173 & 8,42 \\
E15 & 0,2476 & 0,2192 & 0,0284 & 11,47 \\
E16 & 0,1770 & 0,1604 & 0,0166 & 9,38 \\
\hline
\end{tabular}




\section{Anexo D}

Tratamento III do método "mini-agar-block" - resultados de perda de massa obtidos para as cinco espécies de madeira submetidas ao apodrecimento por Gloeophyllum trabeum 
Tabela 20. Tratamento III do método "mini-agar-block" - resultados obtidos para aroeira (Astronium sp)

\begin{tabular}{ccccc}
\hline observação & Mi (g) & Mf (g) & Mi-Mf (g) & perda de massa (\%) \\
\hline A49 & 0,3065 & 0,3040 & 0,0025 & 0,82 \\
A50 & 0,3282 & 0,3252 & 0,0030 & 0,91 \\
A51 & 0,3419 & 0,3382 & 0,0037 & 1,08 \\
A52 & 0,3374 & 0,3338 & 0,0036 & 1,07 \\
A53 & 0,3165 & 0,3134 & 0,0031 & 0,98 \\
A54 & 0,3655 & 0,3613 & 0,0042 & 1,15 \\
A55 & 0,3083 & 0,3046 & 0,0037 & 1,20 \\
A56 & 0,3206 & 0,3178 & 0,0028 & 0,87 \\
A57 & 0,3175 & 0,3145 & 0,0030 & 0,94 \\
A58 & 0,3137 & 0,3111 & 0,0026 & 0,83 \\
A59 & 0,3236 & 0,3212 & 0,0024 & 0,74 \\
A60 & 0,3796 & 0,3760 & 0,0036 & 0,95 \\
A61 & 0,3169 & 0,3141 & 0,0028 & 0,88 \\
A62 & 0,3242 & 0,3205 & 0,0037 & 1,14 \\
A63 & 0,3078 & 0,3049 & 0,0029 & 0,94 \\
A64 & 0,3872 & 0,3841 & 0,0031 & 0,80 \\
\hline
\end{tabular}

Tabela 21. Tratamento III do método "mini-agar-block" - resultados obtidos para angico-preto (Anadenanthera sp)

\begin{tabular}{ccccc}
\hline observação & Mi (g) & Mf (g) & Mi-Mf (g) & perda de massa (\%) \\
\hline B49 & 0,3265 & 0,3204 & 0,0061 & 1,87 \\
B50 & 0,3516 & 0,3438 & 0,0078 & 2,22 \\
B51 & 0,3394 & 0,3337 & 0,0057 & 1,68 \\
B52 & 0,3792 & 0,3737 & 0,0055 & 1,45 \\
B53 & 0,3540 & 0,3478 & 0,0062 & 1,75 \\
B54 & 0,3131 & 0,3084 & 0,0047 & 1,50 \\
B55 & 0,3795 & 0,3724 & 0,0071 & 1,87 \\
B56 & 0,3148 & 0,3097 & 0,0051 & 1,62 \\
B57 & 0,3393 & 0,3349 & 0,0044 & 1,30 \\
B58 & 0,3658 & 0,3618 & 0,0040 & 1,09 \\
B59 & 0,3296 & 0,3254 & 0,0042 & 1,27 \\
B60 & 0,3538 & 0,3486 & 0,0052 & 1,47 \\
B61 & 0,3164 & 0,3124 & 0,0040 & 1,26 \\
B62 & 0,3404 & 0,3357 & 0,0047 & 1,38 \\
B63 & 0,3340 & 0,3296 & 0,0044 & 1,32 \\
B64 & 0,3595 & 0,3547 & 0,0048 & 1,34 \\
\hline
\end{tabular}


Tabela 22. Tratamento III do método "mini-agar-block" - resultados obtidos para jatobá (Hymenaea sp)

\begin{tabular}{ccccc}
\hline observação & Mi (g) & Mf (g) & Mi-Mf (g) & perda de massa (\%) \\
\hline C49 & 0,2616 & 0,2561 & 0,0055 & 2,10 \\
C50 & 0,2775 & 0,2713 & 0,0062 & 2,23 \\
C51 & 0,2742 & 0,2693 & 0,0049 & 1,79 \\
C52 & 0,2687 & 0,2642 & 0,0045 & 1,67 \\
C53 & 0,2645 & 0,2600 & 0,0045 & 1,70 \\
C54 & 0,2787 & 0,2742 & 0,0045 & 1,61 \\
C55 & 0,3040 & 0,2987 & 0,0053 & 1,74 \\
C56 & 0,2488 & 0,2453 & 0,0035 & 1,41 \\
C57 & 0,2455 & 0,2417 & 0,0038 & 1,55 \\
C58 & 0,2572 & 0,2512 & 0,0060 & 2,33 \\
C59 & 0,2979 & 0,2934 & 0,0045 & 1,51 \\
C60 & 0,2600 & 0,2557 & 0,0043 & 1,65 \\
C61 & 0,2604 & 0,2557 & 0,0047 & 1,80 \\
C62 & 0,2522 & 0,2476 & 0,0046 & 1,82 \\
C63 & 0,2443 & 0,2375 & 0,0068 & 2,78 \\
C64 & 0,2356 & 0,2311 & 0,0045 & 1,91 \\
\hline
\end{tabular}

Tabela 23. Tratamento III do método "mini-agar-block" - resultados obtidos para peroba-rosa (Aspidosperma polyneuron)

\begin{tabular}{ccccc}
\hline observação & Mi (g) & Mf (g) & Mi-Mf (g) & perda de massa (\%) \\
\hline D49 & 0,2435 & 0,2374 & 0,0061 & 2,51 \\
D50 & 0,2318 & 0,2261 & 0,0057 & 2,46 \\
D51 & 0,2339 & 0,2296 & 0,0043 & 1,84 \\
D52 & 0,2626 & 0,2561 & 0,0065 & 2,48 \\
D53 & 0,2600 & 0,2525 & 0,0075 & 2,88 \\
D54 & 0,2526 & 0,2480 & 0,0046 & 1,82 \\
D55 & 0,2515 & 0,2454 & 0,0061 & 2,43 \\
D56 & 0,2548 & 0,2437 & 0,0111 & 4,36 \\
D57 & 0,2561 & 0,2476 & 0,0085 & 3,32 \\
D58 & 0,2361 & 0,2305 & 0,0056 & 2,37 \\
D59 & 0,2321 & 0,2275 & 0,0046 & 1,98 \\
D60 & 0,2625 & 0,2570 & 0,0055 & 2,10 \\
D61 & 0,2600 & 0,2522 & 0,0078 & 3,00 \\
D62 & 0,2370 & 0,2296 & 0,0074 & 3,12 \\
D63 & 0,2593 & 0,2533 & 0,0060 & 2,31 \\
D64 & 0,2505 & 0,2405 & 0,0100 & 3,99 \\
\hline
\end{tabular}


Tabela 24. Tratamento III do método "mini-agar-block" - resultados obtidos para pinho-do-paraná (Araucaria angustifolia)

\begin{tabular}{ccccc}
\hline observaçåo & Mi (g) & Mf (g) & Mi-Mf (g) & perda de massa (\%) \\
\hline E49 & 0,1860 & 0,1747 & 0,0113 & 6,08 \\
E50 & 0,1659 & 0,1610 & 0,0049 & 2,95 \\
E51 & 0,2145 & 0,2005 & 0,0140 & 6,53 \\
E52 & 0,1908 & 0,1820 & 0,0088 & 4,61 \\
E53 & 0,1829 & 0,1739 & 0,0090 & 4,92 \\
E54 & 0,1920 & 0,1649 & 0,0271 & 14,11 \\
E55 & 0,1944 & 0,1576 & 0,0368 & 18,93 \\
E56 & 0,1854 & 0,1623 & 0,0231 & 12,46 \\
E57 & 0,1759 & 0,0957 & 0,0802 & 45,59 \\
E58 & 0,1794 & 0,1223 & 0,0571 & 31,83 \\
E59 & 0,1850 & 0,0957 & 0,0893 & 48,27 \\
E60 & 0,1913 & 0,1243 & 0,0670 & 35,02 \\
E61 & 0,1952 & 0,1733 & 0,0219 & 11,22 \\
E62 & 0,1751 & 0,1586 & 0,0165 & 9,42 \\
E63 & 0,1886 & 0,1671 & 0,0215 & 11,40 \\
E64 & 0,1853 & 0,1315 & 0,0538 & 29,03 \\
\hline
\end{tabular}




\section{Anexo $\mathrm{E}$}

Tratamento IV do método "mini-agar-block" - resultados de perda de massa obtidos para as cinco espécies de madeira submetidas ao apodrecimento por Gloeophyllum trabeum 
Tabela 25. Tratamento IV do método "mini-agar-block" - resultados obtidos para aroeira (Astronium sp)

\begin{tabular}{ccccc}
\hline observaçåo & Mi (g) & Mf (g) & Mi-Mf (g) & perda de massa (\%) \\
\hline A33 & 0,3569 & 0,3521 & 0,0048 & 1,34 \\
A34 & 0,3217 & 0,3173 & 0,0044 & 1,37 \\
A35 & 0,3770 & 0,3679 & 0,0091 & 2,41 \\
A36 & 0,3218 & 0,3166 & 0,0052 & 1,62 \\
A37 & 0,3017 & 0,2973 & 0,0044 & 1,46 \\
A38 & 0,3161 & 0,3111 & 0,0050 & 1,58 \\
A39 & 0,2983 & 0,2938 & 0,0045 & 1,51 \\
A40 & 0,3826 & 0,3774 & 0,0052 & 1,36 \\
A41 & 0,2785 & 0,2736 & 0,0049 & 1,76 \\
A42 & 0,2770 & 0,2718 & 0,0052 & 1,88 \\
A43 & 0,3637 & 0,3581 & 0,0056 & 1,54 \\
A44 & 0,3188 & 0,3140 & 0,0048 & 1,51 \\
A45 & 0,3443 & 0,3394 & 0,0049 & 1,42 \\
A46 & 0,2993 & 0,2934 & 0,0059 & 1,97 \\
A47 & 0,3430 & 0,3362 & 0,0068 & 1,98 \\
A48 & 0,3124 & 0,3085 & 0,0039 & 1,25 \\
\hline
\end{tabular}

Tabela 26. Tratamento IV do método "mini-agar-block" - resultados obtidos para angico-preto (Anadenanthera sp)

\begin{tabular}{ccccc}
\hline observaçåo & Mi (g) & Mf (g) & Mi-Mf (g) & perda de massa (\%) \\
\hline B33 & 0,3359 & 0,3293 & 0,0066 & 1,96 \\
B34 & 0,3744 & 0,3658 & 0,0086 & 2,30 \\
B35 & 0,3795 & 0,3728 & 0,0067 & 1,77 \\
B36 & 0,3510 & 0,3432 & 0,0078 & 2,22 \\
B37 & 0,3426 & 0,3349 & 0,0077 & 2,25 \\
B38 & 0,3547 & 0,3467 & 0,0080 & 2,26 \\
B39 & 0,3345 & 0,3271 & 0,0074 & 2,21 \\
B40 & 0,3800 & 0,3732 & 0,0068 & 1,79 \\
B41 & 0,3070 & 0,2986 & 0,0084 & 2,74 \\
B42 & 0,3816 & 0,3742 & 0,0074 & 1,94 \\
B43 & 0,3587 & 0,3498 & 0,0089 & 2,48 \\
B44 & 0,3331 & 0,3254 & 0,0077 & 2,31 \\
B45 & 0,3219 & 0,3132 & 0,0087 & 2,70 \\
B46 & 0,3263 & 0,3199 & 0,0064 & 1,96 \\
B47 & 0,3409 & 0,3324 & 0,0085 & 2,49 \\
B48 & 0,3582 & 0,3518 & 0,0064 & 1,79 \\
\hline
\end{tabular}


Tabela 27. Tratamento IV do método "mini-agar-block" - resultados obtidos para jatobá (Hymenaea sp)

\begin{tabular}{ccccc}
\hline observação & Mi (g) & Mf (g) & Mi-Mf (g) & perda de massa (\%) \\
\hline C33 & 0,3124 & 0,3043 & 0,0081 & 2,59 \\
C34 & 0,2548 & 0,2470 & 0,0078 & 3,06 \\
C35 & 0,2817 & 0,2743 & 0,0074 & 2,63 \\
C36 & 0,2400 & 0,2344 & 0,0056 & 2,33 \\
C37 & 0,2682 & 0,2648 & 0,0034 & 1,27 \\
C38 & 0,2707 & 0,2654 & 0,0053 & 1,96 \\
C39 & 0,2531 & 0,2493 & 0,0038 & 1,50 \\
C40 & 0,2694 & 0,2664 & 0,0030 & 1,11 \\
C41 & 0,2522 & 0,2471 & 0,0051 & 2,02 \\
C42 & 0,2515 & 0,2466 & 0,0049 & 1,95 \\
C43 & 0,2655 & 0,2597 & 0,0058 & 2,18 \\
C44 & 0,2673 & 0,2618 & 0,0055 & 2,06 \\
C45 & 0,2512 & 0,2466 & 0,0046 & 1,83 \\
C46 & 0,2643 & 0,2592 & 0,0051 & 1,93 \\
C47 & 0,2820 & 0,2704 & 0,0116 & 4,11 \\
C48 & 0,2664 & 0,2617 & 0,0047 & 1,76 \\
\hline
\end{tabular}

Tabela 28. Tratamento IV do método "mini-agar-block" - resultados obtidos para peroba-rosa (Aspidosperma polyneuron)

\begin{tabular}{ccccc}
\hline observação & Mi (g) & Mf (g) & Mi-Mf(g) & perda de massa (\%) \\
\hline D33 & 0,2703 & 0,2637 & 0,0066 & 2,44 \\
D34 & 0,2695 & 0,2617 & 0,0078 & 2,89 \\
D35 & 0,2611 & 0,2554 & 0,0057 & 2,18 \\
D36 & 0,2172 & 0,2124 & 0,0048 & 2,21 \\
D37 & 0,2569 & 0,2500 & 0,0069 & 2,69 \\
D38 & 0,2655 & 0,2600 & 0,0055 & 2,07 \\
D39 & 0,2588 & 0,2545 & 0,0043 & 1,66 \\
D40 & 0,2570 & 0,2512 & 0,0058 & 2,26 \\
D41 & 0,2548 & 0,2440 & 0,0108 & 4,24 \\
D42 & 0,2423 & 0,2330 & 0,0093 & 3,84 \\
D43 & 0,2772 & 0,2704 & 0,0068 & 2,45 \\
D44 & 0,2350 & 0,2297 & 0,0053 & 2,26 \\
D45 & 0,2430 & 0,2393 & 0,0037 & 1,52 \\
D46 & 0,2339 & 0,2295 & 0,0044 & 1,88 \\
D47 & 0,2511 & 0,2477 & 0,0034 & 1,35 \\
D48 & 0,2676 & 0,2602 & 0,0074 & 2,77 \\
\hline
\end{tabular}


Tabela 29. Tratamento IV do método "mini-agar-block" - resultados obtidos para pinho-do-paraná (Araucaria angustifolia)

\begin{tabular}{ccccc}
\hline observaçăo & Mi (g) & Mf (g) & Mi-Mf (g) & perda de massa (\%) \\
\hline E33 & 0,174 & 0,144 & 0,030 & 17,07 \\
E34 & 0,168 & 0,163 & 0,005 & 2,91 \\
E35 & 0,210 & 0,171 & 0,039 & 18,71 \\
E36 & 0,190 & 0,124 & 0,066 & 34,88 \\
E37 & 0,172 & 0,093 & 0,079 & 45,93 \\
E38 & 0,182 & 0,127 & 0,055 & 30,15 \\
E39 & 0,186 & 0,114 & 0,072 & 38,65 \\
E40 & 0,184 & 0,108 & 0,076 & 41,37 \\
E41 & 0,197 & 0,121 & 0,076 & 38,58 \\
E42 & 0,184 & 0,176 & 0,007 & 3,92 \\
E43 & 0,213 & 0,165 & 0,048 & 22,69 \\
E44 & 0,197 & 0,162 & 0,035 & 17,55 \\
E45 & 0,190 & 0,099 & 0,090 & 47,65 \\
E46 & 0,180 & 0,102 & 0,079 & 43,54 \\
E47 & 0,179 & 0,132 & 0,047 & 26,08 \\
E48 & 0,218 & 0,198 & 0,020 & 9,05 \\
\hline
\end{tabular}




\section{REFERÊNCIAS BIBLIOGRÁFICAS}

AMBURGEY, $T$. Observations on the soil-block and agar-block methods of evaluating wood decay. Material und Organismen, v. 11, n. 4, p. 273$277,1976$.

AMBURGEY, T. Soil effect on soil-block wood decay tests. Material und Organismen, v. 13, n. 4, p. 245-251, 1978.

AMERICAN SOCIETY FOR TESTING AND MATERIAL - ASTM. Standard method for accelerated laboratory test of natural decay resistance of woods: ASTM D 2017-81(86).

AZEVEDO, P.R. A influência dos fenóis do creosoto na preservaçăo das madeiras. São Paulo, 1943. 12 p. (IPT, 166).

BLANKENHORN, P.R., BALDWIN, R.C., MERRIL Jr., W., OTTONE,S.P. Calorimetric analysis of fungal degraded wood. Wood Science, v. 13, n. 1, p. 26-31, Jul. 1980.

BRAVERY, A.F., LAVERS, G.M. Strength properties of decayed softwood measured on miniature test beam. International Biodeterioration Bulletin, v. 7, n. 3, p. 129-141, Mar. 1971. 
BRAVERY, A.F. Methods for assessing the efficacy of fungicides for wood and wood products. In: HOPTON, J.W., HILL, E.C. (Ed.). Industrial microbiological testing. Oxford: Blackwell Scientific, 1987. p. 1-22.

BRAVERY, A.F. A miniaturised wood-block test for the rapid evaluation of wood preservatives fungicides. In: ANNUAL MEETING, 1978. Proceedings. Stockholm: IRG, 1978. (IRG/WP/2113).

BUILDING RESEARCH ESTABLISHMENT - BRE. House inspection for dampness: a first step to remedial treatment for wood rot. Garston, 1988. 4p. (IP, 19/88).

BUILDING RESEARCH ESTABLISHMENT - BRE. The natural durability classification of timber. Garston, 1969. 4p. (TN, 40).

CAVALCANTE, M.S., LOPEZ, G.A.C., MONTAGNA, R.G., FOSCO MUCCI, M.E.S. Natural durability of wood in ground contact - a correlation between field and laboratory tests. In: ANNUAL MEETING, 16., Guarujá, 1985. Proceedings. Stockholm: IRG, 1985. (IRG/WP/2182).

CAVALCANTE, M.S., MONTAGNA, R.G., LOPEZ, G.A.C., FOSCO MUCCI, E.S. Durabilidade natural de madeiras em contato com o solo II. In: CONGRESSO NACIONAL SOBRE ESSÉNCIAS NATIVAS, 1., Campos do Jordão, 1982. Anais. São Paulo: IF, 1982. p. 1383-1394. 
CAVALCANTE, M.S., MONTAGNA, R.G., MILANO, S., FOSCO MUCCI, E.S. Durabilidade natural de madeiras em contato com o solo. Boletim Técnico IF, v. 29, p. 1-15, jun. 1978.

CAVALCANTE, M.S. Métodos de avaliação da resistência de madeira ao ataque de fungos xilófagos. Preservaçāo de Madeiras, São Paulo, v. 2, n. 1, p. 27-47, jan./dez. 1971.

COMITE EUROPEEN DE NORMALISATION - CEN. Détermination du seuil d'efficacité contre les champignons basidiomycètes lignivores cultivés sur milieu gelose: EN 113-80, Brussels, 1980. p. 26.

COMITE EUROPEEN DE NORMALISATION - CEN. Wood and wood based products - Natural durability of wood - Part 2: Natural durability and treatability of selected wood species of importance in Europe: EN 350-2, Brussels, 1990. $43 \mathrm{p}$.

DA COSTA, E.W.B. Natural decay resistance of wood. In: LIESE, W. (Ed.) Biological transformation of wood by microorganisms. Berlin: Springer-Verlag, 1975. p. 101-117.

DICKINSON, D.J. A new tecnnique for sreening fungicide for wood preservation. International Biodeterioration Bulletin, v. 10, n. 2, p. 49$51,1974$. 
EATON, R.A., HALE, M.D.C. Wood: decay, pests and protection. London: Chapman \& Hall, 1993 546p.

FOJUTOWSKY, A., ZIELINSKI, M.H. Grenzwert von Holzschutzmitteln gegenuber Basidiomycetes - ein Versuch zur Verkurzung der Bestimmungszeit. Holztechnologie, v. 27, n. 5, p. 236-238, 1986.

FOSCO MUCCI, E.S., LOPEZ, G.A.C., MONTAGNA, R.G. Durabilidade natural de madeiras em contato com o solo IV. In: CONGRESSO NACIONAL SOBRE ESSÉNCIAS NATIVAS, 2., São Paulo, 1992. Anais. São Paulo: IF, 1992.

FREITAS, A.R. Método de avaliação de preservativo em laboratório. Preservação de Madeiras, v. 1, n. 3, p. 151-173, jul./set 1970.

GHILARDI, E. Métodos de apodrecimento acelerado adotado no IPT. São Paulo, 1961. 12p. (IPT, 682).

HIGHLEY, T.L. Changes in chemical components of hardwood and softwood by brown-rot fungi. Material und Organismen, v. 22, n. 1, p. 39-45, 1987.

INSTITUTO DE PESQUISAS TECNOLÓGICAS DO ESTADO DE SÃO PAULO S.A. - IPT. Métodos de ensaios adotados no IPT para o estudo de madeiras nacionais. São Paulo, 1956. 60 p. (IPT, 31). 
LEPAGE, E.S. Método padrão sugerido pela IUFRO para ensaios de campo com estacas de madeira. Preservação de Madeiras, v. 1, n. 4, p. 205216, out./dez. 1970.

LEPAGE, E.S. Comparação da resistência natural de madeira através de ensaio de campo e de laboratório. Boletim ABPM, n. 6, nov. 1983.

MANIERI, C., CHIMELO, J.P. Fichas de características das madeiras brasileiras. 2. ed. São Paulo, 1986. 418 p. (IPT, 1791).

MILANO,S., CHIMELO, J.P., BONONI, V.L.R. Decay fungi collected in Brazil from sleepers during the air seasoning period. In: SYMPOSIUM OF THE INTERNATIONAL UNION OF FORESTRY RESEARCH ORGANIZATIONS, Guarujá, 1985. Anais. IUFRO, 1985.

MONTEIRO, M.B.B., BRAZOLIN, S., CATANOZI, G. Comparison between agar-block and soil-block methods for wood-destroying basidiomycetes. In: ANNUAL MEETING, 23., Harrogate, 1992. Proceedings. Stockholm: IRG, 1992. (IRGMP/2401-92).

RAYNER, A.D.M., BODDY, L. Fungal decomposition of wood: its biology and ecology. Chichester: John Wiley, 1988. $587 \mathrm{p}$. 
63

RUYOOKA, D.B.A., GRIFFIN, D.M. Variations in the Natural Resistance of timber - II. Effect of wood-rotting fungi on the natural resistance of selected eucalypt timber under laboratory conditions. Material and Organismen, v. 15, n. 3, p. $195-205,1980$.

UNDERWOOD, A.J. Techniques of analysis of variance in experimental marine biology and ecology. In: BARNES, M.(Ed.) Oceanogr. Mar. Biol. Ann. Rev. Aberdeen: University Press, 1981. v. 19, p. 513-605. 


\section{Apêndice 1}

Método "soil-block"- análise de variância e teste de comparação múltipla de médias de Tukey

Legenda:

PM perda de massa, expressa em porcentagem

MADEIRA espécies de madeira

A aroeira

B angico-preto

C jatobá

D peroba-rosa

E pinho-do-paraná 
STATISTICA: ANOVA/MANOVA

data file: SB.STA [ 80 cases with 2 variables ]

VARIABIES :

$\begin{array}{lll}2: & \text { PM } & -9999 \\ \text { 1: } & \text { MADEIRA } & -9999\end{array}$

INDEPENDENT VARIABIES (between-groups factors):

MADEIRA Number of Levels: 5 Codes: level 1: 100-A

level 2: 101-B

level 3: 102-C

level 4: 103-D

level 5: 104-E

DESIGN: 1 - way ANOVA

DEPENDENT: 1 variable:

PM

, fixed effects

BETWEEN: 1-MADEIRA ( 5): A B C D E

WITHIN: none

\begin{tabular}{|c|c|c|c|c|c|c|}
\hline $\begin{array}{l}\text { STAT. } \\
\text { GENERAL }\end{array}$ & \multicolumn{6}{|c|}{$\begin{array}{l}\text { Sumunary of all Effects; design: (sb.sta) } \\
\text { 1-MADEIRA }\end{array}$} \\
\hline Effect & $\underset{\text { Effect }}{\operatorname{df}}$ & $\begin{array}{c}\text { MS } \\
\text { Effect }\end{array}$ & $\begin{array}{l}\mathrm{df} \\
\text { Error }\end{array}$ & $\begin{array}{l}\text { MS } \\
\text { Error }\end{array}$ & $\mathrm{F}$ & p-level \\
\hline 1 & 4 * & $760,5995 *$ & 75 * & 21,16555 * & 35,93573 * &, 000000 * \\
\hline
\end{tabular}




\begin{tabular}{|c|c|c|c|c|c|c|}
\hline \multicolumn{2}{|c|}{$\begin{array}{l}\text { STAT. } \\
\text { GENERAI } \\
\text { MANOVA }\end{array}$} & \multicolumn{5}{|c|}{$\begin{array}{l}\text { Tukey HSD test; variable PM (sb.sta) } \\
\text { Probabilities for Post Hoc Tests } \\
\text { MAIN EFFECT: MADEIRA }\end{array}$} \\
\hline & & $\begin{array}{c}\{1\} \\
1,845634\end{array}$ & $\begin{array}{c}\{2\} \\
1,425707\end{array}$ & $\begin{array}{c}\{3\} \\
1,073406\end{array}$ & $\begin{array}{c}\{4\} \\
2,088039\end{array}$ & $\begin{array}{c}\{5\} \\
17,00072\end{array}$ \\
\hline $\begin{array}{l}\text { A } \\
B \\
C \\
D \\
E\end{array}$ & $\begin{array}{l}\{1\} \\
\{2\} \\
\{3\} \\
\{4\} \\
\{5\}\end{array}$ & $\begin{array}{l}, 999056 \\
, 989479 \\
, 999899 \\
, 000122^{\star}\end{array}$ & $\begin{array}{l}, 999056 \\
, 999556 \\
, 994156 \\
, 000122 \star\end{array}$ & $\begin{array}{l}, 989479 \\
, 999556 \\
, 970876 \\
, 000122 \star\end{array}$ & $\begin{array}{l}, 999899 \\
, 994156 \\
, 970876 \\
, 000122 \star\end{array}$ & $\begin{array}{l}, 000122 \star \\
, 000122 \star \\
, 000122 \star \\
, 000122 *\end{array}$ \\
\hline
\end{tabular}




\begin{abstract}
Apêndice 3
Tratamentos I, II, III e IV do método "mini-agar-block"- análise de variância e teste de comparação múltipla de médias de Tukey
\end{abstract}

PM

perda de massa, expressa em porcentagem

MADEIRA espécies de madeira

A aroeira

B angico-preto

C jatobá

D peroba-rosa

E pinho-do-paraná

CONDICI tipo de condicionamento C câmara climatizada

$S$ estufa

ESTERIL tipo de esterilização $\mathrm{R}$ radiação

AU autoclave 
STATISTICA: ANOVA/MANOVA

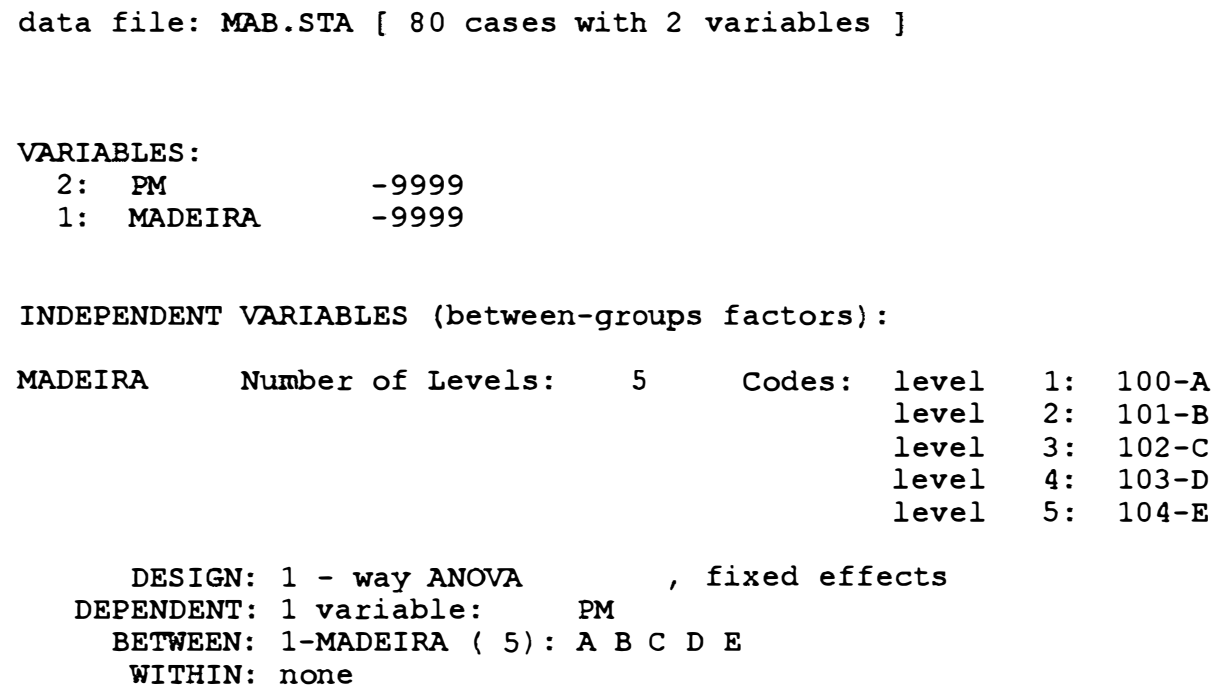

\begin{tabular}{|c|c|c|c|c|c|c|}
\hline $\begin{array}{l}\text { STAT. } \\
\text { GENERAL }\end{array}$ & \multicolumn{6}{|c|}{$\begin{array}{l}\text { Sumunary of all Effects; design: (mab.sta) } \\
\text { 1-MADEIRA }\end{array}$} \\
\hline Effect & $\underset{\text { Effect }}{\operatorname{df}}$ & $\begin{array}{c}\text { MS } \\
\text { Effect }\end{array}$ & $\begin{array}{l}\text { df } \\
\text { Error }\end{array}$ & $\begin{array}{l}\text { MS } \\
\text { Error }\end{array}$ & $\mathrm{F}$ & p-level \\
\hline 1 & 4 * & $1421,314 \star$ & $75^{\star}$ & 30,78287 * & $46,17223^{*}$ &, $000000^{\star}$ \\
\hline
\end{tabular}




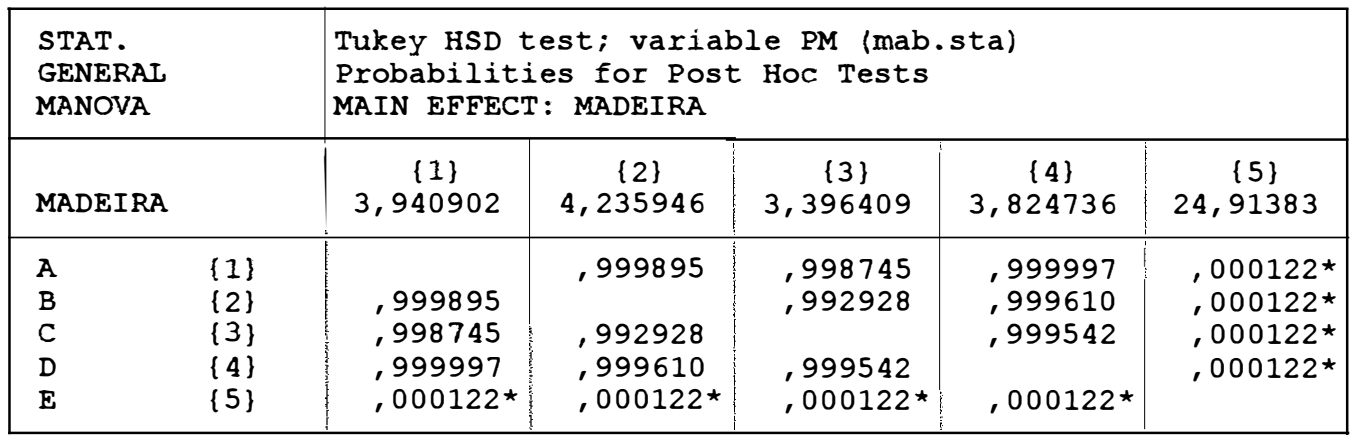




\section{Apêndice 2}

Tratamento I do método "mini-agar-block"- análise de variância e teste de comparação múltipla de médias de Tukey

\section{Legenda:}

PM MADEIRA

A

B

C

D

$\mathrm{E}$ perda de massa, expressa em porcentagem espécies de madeira

aroeira

angico-preto

jatobá

peroba-rosa

pinho-do-paraná 
STATISTICA: ANOVA/MANOVA

data file: MAB-TRAT.STA [ 320 cases with 4 variables ]

$\begin{array}{lll}\text { VARIABLES : } & \\ \text { 4: } & \text { PM } & -9999 \\ \text { 1: } & \text { MADEIRA } & -9999 \\ \text { 2: } & \text { CONDICI } & -9999 \\ \text { 3: } & \text { ESTERIL } & -9999\end{array}$

INDEPENDENT VARIABLES (between-groups factors):

MADEIRA Number of Levels: 5 Codes: level 1: 100-A

level 2: 101-B

level 3: 102-C

level 4: 103-D

CONDICI Number of Levels: 2 Codes: level $5:$ level $1:$ 100-C

level 2: 101-S

ESTERIL Number of Levels: 2 Codes: level 1: 100-R

DESIGN: 3 - way ANOVA , fixed effects

DEPENDENT: 1 variable: PM

BETWEEN: 1-MADEIRA ( 5): A B C D E

2-CONDICI ( 2): C S

3-ESTERIL ( 2): $\mathrm{R} \mathrm{AU}$

WITHIN: none

\begin{tabular}{|c|c|c|c|c|c|c|}
\hline $\begin{array}{l}\text { STAT. } \\
\text { GENERAL }\end{array}$ & \multicolumn{6}{|c|}{$\begin{array}{l}\text { Summary of all Effects; design: (mab-trat.sta) } \\
\text { 1-MADEIRA, 2-CONDICI, 3-ESTERIL }\end{array}$} \\
\hline Effect & $\underset{\text { Effect }}{d f}$ & $\begin{array}{c}\text { MS } \\
\text { Effect }\end{array}$ & $\begin{array}{l}\text { df } \\
\text { Error }\end{array}$ & $\begin{array}{c}\text { MS } \\
\text { Error }\end{array}$ & $\mathbf{F}$ & p-level \\
\hline $\begin{array}{l}1 \\
2 \\
3 \\
12 \\
13 \\
23 \\
123\end{array}$ & $\begin{array}{l}4 \star \\
1 \\
1 \\
4 \\
4 \\
1 \star \\
4 \star\end{array}$ & $\begin{array}{c}4595,458 \star \\
7,655 \\
117,267 \\
57,340 \\
1,558 \\
878,161^{\star} \\
231,713^{\star}\end{array}$ & $\begin{array}{l}300 \star \\
300 \\
300 \\
300 \\
300 \\
300 \star \\
300 \star\end{array}$ & $\begin{array}{l}32,80377 \star \\
32,80377 \\
32,80377 \\
32,80377 \\
32,80377 \\
32,80377 \star \\
32,80377 \star\end{array}$ & $\begin{array}{r}140,0893^{\star} \\
, 2334 \\
3,5748 \\
1,7480 \\
, 0475 \\
26,7701^{\star} \\
7,0636^{\star}\end{array}$ & $\begin{array}{c}0,000000 \star \\
, 629403 \\
, 059626 \\
, 139388 \\
, 995742 \\
, 000000^{\star} \\
, 000019 \star\end{array}$ \\
\hline
\end{tabular}




\begin{tabular}{|c|c|c|c|c|c|c|c|c|}
\hline \multicolumn{4}{|l|}{$\begin{array}{l}\text { STAT. } \\
\text { GENERAL } \\
\text { MANOVA }\end{array}$} & \multicolumn{5}{|c|}{$\begin{array}{l}\text { Tukey HSD test; variable PM (mab-trat.sta) } \\
\text { Probabilities for Post Hoc Tests } \\
\text { INTERACTION: } 1 \times 2 \times 3\end{array}$} \\
\hline MADEIRA & CONDICI & ESTERIL & & $\begin{array}{c}\{1\} \\
1,130824\end{array}$ & $\begin{array}{c}\{2\} \\
3,940902\end{array}$ & $\begin{array}{c}\{3\} \\
1,622351\end{array}$ & $\begin{array}{c}\{4\} \\
, 9570198\end{array}$ & $\begin{array}{c}\{5\} \\
1,542144\end{array}$ \\
\hline A & C & $\mathbf{R}$ & $\{1\}$ & & 998173 & 1,000000 & 1,000000 & 1,000000 \\
\hline A & $\mathrm{C}$ & $\mathrm{AU}$ & $\{2\}$ &, 998173 & & , 999876 &, 996069 &, 999796 \\
\hline A & $\mathrm{S}$ & $\mathrm{R}$ & $\{3\}$ & 1,000000 & , 999876 & & 1,000000 & 1,000000 \\
\hline A & $\mathrm{S}$ & $\mathrm{AU}$ & $\{4\}$ & 1,000000 & 996069 & 1,000000 & & 1,000000 \\
\hline $\mathrm{B}$ & $\mathrm{C}$ & $\mathrm{R}$ & $\{5\}$ & 1,000000 & 999796 & 1,000000 & 1,000000 & \\
\hline B & $\mathrm{C}$ & $\mathrm{AU}$ & $\{6\}$ & , 993608 & 1,000000 &, 999310 &, 987946 & , 998958 \\
\hline B & $\mathrm{s}$ & $\mathrm{R}$ & $\{7\}$ & 1,000000 &, 999999 & 1,000000 & 1,000000 & 1,000000 \\
\hline B & $S$ & $\mathrm{AU}$ & $\{8\}$ & 1,000000 & 999773 & 1,000000 & 1,000000 & 1,000000 \\
\hline $\mathrm{C}$ & $\mathrm{C}$ & $\mathrm{R}$ & $\{9\}$ & 1,000000 &, 983254 & 1,000000 & 1,000000 & 1,000000 \\
\hline $\mathrm{C}$ & $\mathrm{C}$ & $\mathrm{AU}$ & $\{10\}$ & , 999912 & 1,000000 & , 999998 &, 999739 & , 999996 \\
\hline C & $\mathrm{s}$ & $\mathbf{R}$ & $\{11\}$ & 1,000000 & 999998 & 1,000000 & 1,000000 & 1,000000 \\
\hline C & $\mathrm{S}$ & $\mathrm{AU}$ & $\{12\}$ & 1,000000 & 999975 & 1,000000 & 1,000000 & 1,000000 \\
\hline D & C & $\mathbf{R}$ & $\{13\}$ & 1,000000 & 986614 & 1,000000 & 1,000000 & 1,000000 \\
\hline $\mathrm{D}$ & $\mathrm{C}$ & $\mathrm{AU}$ & $\{14\}$ & , 998958 & 1,000000 & , 999943 &, 997622 & , 999902 \\
\hline $\mathrm{D}$ & $\mathrm{S}$ & $\mathbf{R}$ & $\{15\}$ & 1,000000 & 1,000000 & 1,000000 & 1,000000 & 1,000000 \\
\hline $\mathrm{D}$ & $\mathrm{S}$ & $\mathrm{AU}$ & $\{16\}$ & 1,000000 & 1,000000 & 1,000000 & , 999999 & 1,000000 \\
\hline $\mathrm{E}$ & $\mathrm{C}$ & $\mathrm{R}$ & $\{17\}$ &, $000043 \star$ &, $000220 \star$ &, $000043 \star$ &, $000043^{\star}$ &, $000043 \star$ \\
\hline $\mathbf{E}$ & $\mathrm{C}$ & $\mathrm{AU}$ & $\{18\}$ &, $000043 \star$ &, $000043 *$ &, $000043^{\star}$ &, $000043 *$ &, $000043 *$ \\
\hline$E$ & $\mathrm{~S}$ & $\mathrm{R}$ & $\{19\}$ &, $000043 \star$ &, $000043 \star$ &, $000043^{\star}$ &, $000043^{\star}$ &, $000043 *$ \\
\hline$E$ & $\mathrm{~S}$ & $\mathrm{AU}$ & $\{20\}$ &, $000043 *$ &, $000043 \star$ &, $000043 *$ &, $000043 *$ &, $000043 *$ \\
\hline
\end{tabular}

\begin{tabular}{|c|c|c|c|c|c|c|c|c|}
\hline \multicolumn{4}{|l|}{$\begin{array}{l}\text { STAT. } \\
\text { GENERAL } \\
\text { MANOVA }\end{array}$} & \multicolumn{5}{|c|}{$\begin{array}{l}\text { Tukey HSD test; variable PM (mab-trat.sta) } \\
\text { Probabilities for Post Hoc Tests } \\
\text { INTERACTION: } 1 \times 2 \times 3\end{array}$} \\
\hline MADEIRA & CONDICI & ESTERIL & & $\begin{array}{c}\{6\} \\
4,235946\end{array}$ & $\begin{array}{c}\{7\} \\
2,197914\end{array}$ & $\begin{array}{c}\{8\} \\
1,524493\end{array}$ & $\begin{array}{c}\{9\} \\
, 5635942\end{array}$ & $\begin{array}{c}\{10\} \\
3,396409\end{array}$ \\
\hline A & C & $\mathbf{R}$ & $\{1\}$ & , 993608 & 1,000000 & 1,000000 & 1,000000 & , 999912 \\
\hline A & $\mathrm{C}$ & $A U$ & $\{2\}$ & 1,000000 & , 999999 & , 999773 &, 983254 & 1,000000 \\
\hline A & $\mathrm{S}$ & $\mathrm{R}$ & $\{3\}$ & , 999310 & 1,000000 & 1,000000 & 1,000000 & 999998 \\
\hline A & $\mathrm{S}$ & $\mathrm{AU}$ & $\{4\}$ & 987946 & 1,000000 & 1,000000 & 1,000000 & 999739 \\
\hline B & $\mathrm{C}$ & $\mathrm{R}$ & $\{5\}$ & 998958 & 1,000000 & 1,000000 & 1,000000 & 999996 \\
\hline B & $\mathrm{C}$ & $\mathrm{AU}$ & $\{6\}$ & & , 999983 & , 998863 &, 960112 & 1,000000 \\
\hline B & $\mathrm{S}$ & $\mathrm{R}$ & $\{7\}$ & , 999983 & & 1,000000 & 1,000000 & 1,000000 \\
\hline B & $\mathrm{s}$ & $\mathrm{AU}$ & $\{8\}$ & 998863 & 1,000000 & & 1,000000 & , 999996 \\
\hline $\mathrm{C}$ & $\mathrm{C}$ & $\mathrm{R}$ & $\{9\}$ &, 960112 & 1,000000 & 1,000000 & & 997970 \\
\hline $\mathrm{C}$ & $\mathrm{C}$ & $\mathrm{AU}$ & $\{10\}$ & 1,000000 & 1,000000 & , 999996 & , 997970 & \\
\hline $\mathrm{C}$ & $\mathrm{S}$ & $\mathrm{R}$ & $\{11\}$ & , 999974 & 1,000000 & 1,000000 & 1,000000 & 1,000000 \\
\hline $\mathrm{C}$ & $\mathrm{S}$ & $\mathrm{AU}$ & $\{12\}$ & , 999813 & 1,000000 & 1,000000 & 1,000000 & 1,000000 \\
\hline $\mathrm{D}$ & $\mathrm{C}$ & $\mathrm{R}$ & $\{13\}$ & 966829 & 1,000000 & 1,000000 & 1,000000 &, 998522 \\
\hline D & $\mathrm{C}$ & $\mathrm{AU}$ & $\{14\}$ & 1,000000 & 1,000000 & , 999890 &, 988667 & 1,000000 \\
\hline D & $\mathrm{S}$ & $\mathbf{R}$ & $\{15\}$ & , 999997 & 1,000000 & 1,000000 & , 999996 & 1,000000 \\
\hline $\mathrm{D}$ & $S$ & $\mathrm{AU}$ & $\{16\}$ & 1,000000 & 1,000000 & 1,000000 & , 999968 & 1,000000 \\
\hline $\mathbf{E}$ & $\mathrm{C}$ & $\mathbf{R}$ & $\{17\}$ &, $000411 \star$ &, $000044 *$ &, $000043 \star$ &, $000043 *$ &, $000085 \star$ \\
\hline$E$ & $\mathrm{C}$ & $\mathrm{AU}$ & $\{18\}$ &, $000043 *$ &, $000043^{\star}$ &, $000043 *$ &, $000043 *$ &, $000043^{\star}$ \\
\hline$E$ & $\mathrm{~s}$ & $\mathrm{R}$ & $\{19\}$ &, $000043 \star$ &, $000043 *$ &, $000043 *$ &, $000043 *$ &, $000043 *$ \\
\hline$E$ & $S$ & $\mathrm{AU}$ & $\{20\}$ &, $000043^{\star}$ &, $000043^{\star}$ &, $000043 *$ &, $000043 \star$ &, $000043 \star$ \\
\hline
\end{tabular}




\begin{tabular}{|c|c|c|c|c|c|c|c|c|}
\hline \multicolumn{4}{|l|}{$\begin{array}{l}\text { STAT } \\
\text { GENERAL } \\
\text { MANOVA }\end{array}$} & \multicolumn{5}{|c|}{$\begin{array}{l}\text { Tukey HSD test; variable PM (mab-trat.sta) } \\
\text { Probabilities for Post Hoc Tests } \\
\text { INTERACTION: } 1 \times 2 \times 3\end{array}$} \\
\hline MADEIRA & CONDICI & EST & & $\begin{array}{c}\{11\} \\
2,144133\end{array}$ & $\begin{array}{c}\{12\} \\
1,852000\end{array}$ & $\begin{array}{c}\{13\} \\
, 6312824\end{array}$ & $\begin{array}{c}\{14\} \\
3,824736\end{array}$ & $\begin{array}{c}\{15\} \\
2,419572\end{array}$ \\
\hline A & $\mathrm{C}$ & $\mathrm{R}$ & $\{1\}$ & 1,000000 & 1,000000 & 1,000000 & , 998958 & 1,000000 \\
\hline A & C & $\mathrm{AU}$ & $\{2\}$ &, 999998 & 999975 & 986614 & 1,000000 & 1,000000 \\
\hline A & $\mathrm{s}$ & $\mathbf{R}$ & $\{3\}$ & 1,000000 & 1,000000 & 1,000000 & 999943 & 1,000000 \\
\hline A & $\mathrm{s}$ & $\mathrm{AU}$ & $\{4\}$ & 1,000000 & 1,000000 & 1,000000 &, 997622 & 1,000000 \\
\hline B & C & $\mathrm{R}$ & $\{5\}$ & 1,000000 & 1,000000 & 1,000000 & , 999902 & 1,000000 \\
\hline B & C & $\mathrm{AU}$ & $\{6\}$ & , 999974 & , 999813 & , 966829 & 1,000000 & , 999997 \\
\hline B & $\mathrm{s}$ & $\mathrm{R}$ & $\{7\}$ & 1,000000 & 1,000000 & 1,000000 & 1,000000 & 1,000000 \\
\hline B & $\mathrm{S}$ & AU & $\{8\}$ & 1,000000 & 1,000000 & 1,000000 & , 999890 & 1,000000 \\
\hline C & C & $\mathrm{R}$ & $\{9\}$ & 1,000000 & 1,000000 & 1,000000 &, 988667 & , 999996 \\
\hline C & C & AU & $\{10\}$ & 1,000000 & 1,000000 & , 998522 & 1,000000 & 1,000000 \\
\hline C & $\mathrm{s}$ & $\mathrm{R}$ & $\{11\}$ & & 1,000000 & 1,000000 & 999999 & 1,000000 \\
\hline C & $\mathrm{S}$ & $\mathrm{AU}$ & $\{12\}$ & 1,000000 & & 1,000000 & , 999990 & 1,000000 \\
\hline D & C & $\mathbf{R}$ & $\{13\}$ & 1,000000 & 1,000000 & & , 991098 & , 999998 \\
\hline D & C & $\mathrm{AU}$ & $\{14\}$ & , 999999 & 999990 & , 991098 & & 1,000000 \\
\hline D & $\mathrm{s}$ & $\mathrm{R}$ & $\{15\}$ & 1,000000 & 1,000000 & , 999998 & 1,000000 & \\
\hline D & $\mathbf{S}$ & AU & $\{16\}$ & 1,000000 & 1,000000 & 999980 & 1,000000 & 1,000000 \\
\hline $\mathbf{E}$ & C & $\mathrm{R}$ & $\{17\}$ &, $000044 *$ &, $000043 \star$ &, $000043^{\star}$ &, $000174 \star$ &, $000045 *$ \\
\hline $\mathbf{E}$ & C & $\mathrm{AU}$ & $\{18\}$ &, $000043^{\star}$ &, $000043^{\star}$ &, $000043^{\star}$ &, $000043 \star$ &, $000043 *$ \\
\hline $\mathbf{E}$ & $\mathrm{s}$ & $\mathrm{R}$ & $\{19\}$ &, $000043^{\star}$ &, $000043 *$ &, $000043 \star$ &, $000043 \star$ &, $000043 *$ \\
\hline$E$ & $\mathrm{~S}$ & $\mathrm{AU}$ & $\{20\}$ &, $000043 *$ &, $000043 \star$ &, $000043 *$ &, $000043^{\star}$ &, $000043^{\star}$ \\
\hline
\end{tabular}

\begin{tabular}{|c|c|c|c|c|c|c|c|c|}
\hline \multicolumn{4}{|l|}{$\begin{array}{l}\text { STAT. } \\
\text { GENERAL } \\
\text { MANOVA }\end{array}$} & \multicolumn{5}{|c|}{$\begin{array}{l}\text { Tukey HSD test; variable PM (mab-trat.sta) } \\
\text { Probabilities for Post Hoc Tests } \\
\text { INTERACTION: } 1 \times 2 \times 3\end{array}$} \\
\hline MADEIRA & CONDICI & ESTERIL & & $\begin{array}{c}\{16\} \\
2,685101\end{array}$ & $\begin{array}{c}\{17\} \\
13,82461\end{array}$ & $\begin{array}{c}\{18\} \\
24,91383\end{array}$ & $\begin{array}{c}\{19\} \\
27,42091\end{array}$ & $\begin{array}{c}\{20\} \\
18,27407\end{array}$ \\
\hline A & $\mathrm{C}$ & $\mathrm{R}$ & $\{1\}$ & 1,000000 &, $000043 \star$ &, $000043^{\star}$ &, $000043 *$ &, $000043 \star$ \\
\hline A & $\mathrm{C}$ & $\mathrm{AU}$ & $\{2\}$ & 1,000000 & $000220 \star$ &, $000043 \star$ &, $000043 \star$ & $.000043 *$ \\
\hline A & $\mathrm{s}$ & $\mathrm{R}$ & $\{3\}$ & 1,000000 &, $000043 *$ &, $000043 \star$ &, $000043 *$ &, $000043 *$ \\
\hline A & $\mathrm{s}$ & $\mathrm{AU}$ & $\{4\}$ & , 999999 &, $000043 \star$ &, $000043 \star$ &, $000043 *$ &, $000043 \star$ \\
\hline B & $\mathrm{C}$ & $\mathrm{R}$ & $\{5\}$ & 1,000000 &, $000043 \star$ &, $000043 \star$ &, $000043 *$ &, $000043 \star$ \\
\hline B & $\mathrm{C}$ & $\mathrm{AU}$ & $\{6\}$ & 1,000000 &, $000411 *$ &, $000043^{\star}$ &, $000043 *$ & $.000043 \star$ \\
\hline $\mathrm{B}$ & $\mathrm{s}$ & $\mathrm{R}$ & $\{7\}$ & 1,000000 & $000044 \star$ &, $000043 *$ &, $000043 \star$ &, $000043 \star$ \\
\hline B & $\mathrm{s}$ & $\mathrm{AU}$ & $\{8\}$ & 1,000000 &, $000043 *$ &, $000043^{\star}$ &, $000043 \star$ &, $000043 \star$ \\
\hline $\mathrm{C}$ & $\mathrm{C}$ & $\mathrm{R}$ & $\{9\}$ & , 999968 &, $000043 \star$ &, $000043 \star$ &, $000043 \star$ &, $000043 *$ \\
\hline $\mathrm{C}$ & $\mathrm{C}$ & $\mathrm{AU}$ & $\{10\}$ & 1,000000 &, $000085 \star$ &, $000043 \star$ &, $000043 \star$ &, $000043 \star$ \\
\hline C & $\mathrm{s}$ & $\mathbf{R}$ & $\{11\}$ & 1,000000 &, $000044 \star$ &, $000043 \star$ &, $000043 \star$ & $000043 *$ \\
\hline C & $\mathrm{s}$ & $\mathrm{AU}$ & $\{12\}$ & 1,000000 &, $000043 \star$ &, $000043^{\star}$ &, $000043^{\star}$ &, $000043 \star$ \\
\hline D & C & $\mathrm{R}$ & $\{13\}$ &, 999980 &, $000043 \star$ &, $000043^{\star}$ &, $000043 \star$ &, $000043 \star$ \\
\hline $\mathrm{D}$ & $\mathrm{C}$ & $\mathrm{AU}$ & $\{14\}$ & 1,000000 & $000174 \star$ &, $000043 \star$ &, $000043 \star$ &, $000043 \star$ \\
\hline $\mathrm{D}$ & $\mathrm{S}$ & $\mathrm{R}$ & $\{15\}$ & 1,000000 &, $000045 \star$ &, $000043^{\star}$ &, $000043 \star$ &, $000043 *$ \\
\hline $\mathrm{D}$ & $\mathrm{s}$ & $\mathrm{AU}$ & $\{16\}$ & & $000048 \star$ &, $000043^{\star}$ &, $000043 \star$ &, $000043 \star$ \\
\hline $\mathrm{E}$ & $\mathrm{C}$ & $\mathrm{R}$ & $\{17\}$ &, 000048 * & &, $000049 \star$ &, $000043 \star$ & 802557 \\
\hline$E$ & C & AU & $\{18\}$ &, $000043 *$ &, $000049 \star$ & & 999615 & 112259 \\
\hline $\mathrm{E}$ & $\mathrm{s}$ & $\mathrm{R}$ & $\{19\}$ &, $000043^{\star}$ &, $000043 \star$ & , 999615 & &, $001092 \star$ \\
\hline $\mathrm{E}$ & $\mathrm{s}$ & $\mathrm{AU}$ & $\{20\}$ &, $000043^{\star}$ & 802557 & 112259 & , 001092* & \\
\hline
\end{tabular}

